\title{
A SUMMARY OF THE WORK ASSOCIATED WITH THE SOLUTION AND UNDERSTANDING OF STRINGER-TYPE CORROSION IN ZIRCALOY-2 AND -3
}

J. G. Goodwin - L. S. Rubenstein - J. D. Grozier - F. L. Shubert

Contract AT-11-1-GEN-14

April 1959

Price $\$ .75$

Available from the Office of Technical Services,

Department of Commerce,

Washington 25, D. C.

This document is PUBLICL $Y$ RELEASABLE

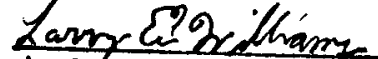

Authbrizing Official

Date: $02 / 15 / 2006$

\author{
BETTIS PLANT • PITTSBURGH, PA. \\ OPERATED FOR THE U.S. ATOMIC ENERGY COMMISSION BY \\ BETTIS ATOMIC POWER DIVISION, WESTINGHOUSE ELECTRIC CORPORATION
}




\section{DISCLAIMER}

This report was prepared as an account of work sponsored by an agency of the United States Government. Neither the United States Government nor any agency Thereof, nor any of their employees, makes any warranty, express or implied, or assumes any legal liability or responsibility for the accuracy, completeness, or usefulness of any information, apparatus, product, or process disclosed, or represents that its use would not infringe privately owned rights. Reference herein to any specific commercial product, process, or service by trade name, trademark, manufacturer, or otherwise does not necessarily constitute or imply its endorsement, recommendation, or favoring by the United States Government or any agency thereof. The views and opinions of authors expressed herein do not necessarily state or reflect those of the United States Government or any agency thereof. 


\section{DISCLAIMER}

Portions of this document may be illegible in electronic image products. Images are produced from the best available original document. 


\section{SPECIAL EXTERNAL DISTRIBUTION}

Manager, Pittsburgh Naval Reactors Operations Office, AEC

Allegheny Ludlum Steel Corp., Dr. T. T. Magel

Ames Laboratory, Iowa State College, Dr. F. H. Spedding

Argonne National Laboratory, Dr. Frank Foote

Armour Research Foundation, Mr. D. J. McPherson

Atomics International Inc. , Dr. John Howe

Babcock \& Wilcox, Mr. N. C. Jessen

Battelle Memorial Institute, Dr. R. W. Dayton

Bridgeport Brass Co., Mr. R. S. French

Budd Co., Mr. H. Van Sciver

Carborundum Metals Co., Mr. N. C. Bartholomew

Chase Brass and Copper Co., Mr. D. K. Crampton

Columbia National Corp., Mr. G. Kiddoo

Combustion Engineering, Reactor Development Division, Mr. George M. Chambers

D. E. Makepeace Co., Mr. H. Barney

Hanford Atomic Products Operation, General Electric Co., Mr. J. Cadwell

Hanford Operations Office, Mr. J. E. Travis

Harvey Aluminum Co. , Mr. G. A. Moudry

Knolls Atomic Power Laboratory, Dr. F. E. Crever

Linde Co., Mr. J. F. Galbraith

Materials Research Corp., Dr. S. Weinig

Metals and Control Corp., Mr. C. L. Wilson

Nuclear Metals, Dr. A. R. Kaufmann

Oak Ridge National Laboratory, Mr. John Frye

Olin Mathieson Corp., Mr. E. Hartshorne

Oregon Metallurgical Co., Mr. S. M. Shelton

Simonds Saw and Steel Co., Mr. C. H. Emery

Superior Steel Co., Mr. W. Keene

Superior Tube Corp., Mr. R. H. Gabel

U. S. Bureau of Mines, Mr. Mark L. Wright

Wah Chang Corp., Mr. S. Yih

Westinghouse Atomic Fuel Department, Mr. I. Fox

Westinghouse Metals Plant, Mr. R. D. Rowley

Wolverine Tube, Mr. J. S. Rodgers

TOTAL

This report was prepared as an account of Government sponsored work. Neither the United States, nor the Commission, nor any person acting on behalf of the Commission:

A. Makes any warranty or representation, expressed or implied, with respect to the accuracy, completeness, or usefulness of the information contained in this report, or that the use of any information, apparatus, method, or process disclosed in this report may not infringe privately owned rights; or

B. Assumes any liabilities with respect to the use of, or for damages resulting from the use of any information, apparatus, method, or process disclosed in this report.

As used in the above, "person acting on behalf of the Commission" includes any employe or contractor of the commission, or employe of such contractor, to the extent that such employe or contractor of the Commission, or employe of such contractor prepares, disseminates, or provides access to, any information pursuant to his employment or contract with the Commission, or his employment with such contractor. 


\section{CONTENTS}

$\begin{array}{lr}\text { INTRODUCTION } & 1 \\ \text { INVESTIGATIONS } & 3 \\ \text { Zircaloy-3 } & 3 \\ \text { Chemical Analysis } & 3 \\ \text { Melting History } & 3 \\ \text { Fabrication History } & 4 \\ \text { Zircaloy-3 Development Program History } & 4 \\ \text { Corrosion Testing } & 4 \\ \text { Metallographic Examination and Heat } & 5 \\ \text { Treatment Studies } & 7 \\ \text { Commercial Homogenization } & 8 \\ \text { Cooling Rate Studies } & 10 \\ \text { Zircaloy-2 } & 10 \\ \text { Corrosion Problem } & 10 \\ \text { Statistical Analysis of Bettis Records } & 11 \\ \text { Fabrication Studies } & \\ \text { Metallographic Examination and Heat } & 12 \\ \text { Treatment Studies } & \\ \text { Irradiation Penetration and Stringer } & 13 \\ \text { Geometry Studies } & 15 \\ \text { Cooling Rate Studies } & 19 \\ \text { ACKNOSSION } & 21 \\ \text { REFERENCES } & 21\end{array}$


This report summarizes the work performed to eliminate stringertype corrosion from Zircaloy-2 and Zircaloy-3. The investigation included a study of the melting and fabrication variables of the alloys. Netallographic and thermal treatment studies identified the problem to be inert atmosphere melting. Based on this work, a stringer formation mechanism has been postulated.

\section{A SUMMARY OF THE WORK ASSOCIATED WITH THE SOLUTION AND UNDERSTANDING OF STRINGER - TYPE CORROSION IN ZIRCALOY -2 AND - 3}

J. G. Goodwin, L. S. Rubenstein, J. D. Grozier, F. L. Shubert

\section{INTRODUCTION}

Zirconium-base alloys are utilized for fuel cladding in pressurized water reactors because of their low thermal neutron absorption, satisfactory strength at reactor operating temperatures, and excellent corrosion resistance to high temperature water. Zircaloy-2, nominally $1.45 \%$ Sn, $0.125 \% \mathrm{Fe}, 0.100 \% \mathrm{Cr}, 0.050 \% \mathrm{Ni}$, and balance zirconium, has been successfully employed as the fuel cladding material in a number of operating reactors. The corrosion resistance of Zircaloy -2 was satisfactory. However, methods for prolonging reactor core life indicated the need for an alloy with long-time corrosion characteristics superior to those of Zircaloy-2.

An alloy development program, carried out during 1954 and 1955, resulted in an acceptable alloy containing $0.25 \% \mathrm{Sn}, 0.25 \% \mathrm{Fe}$, and balance zirconium, which exhibited the desired improvement in long-time corrosion characteristics. This alloy, termed Zircaloy -3 , was studied in an extensive evaluation program involving both laboratory and commercial facilties to ensure that the initial findings were correct. Zircaloy-3 ingots for the evaluation program were melted and fabricated by commercial facilities using methods equivalent to those used for Zircaloy-2 production ingots. Melting combinations included the use of sponge from different sources, the use of vacuum and atmosphere melting, and the use of melting facilities of two different vendors. Strip samples from a number of evaluation program ingots were tested in $750^{\circ} \mathrm{F}$, 1500 psi steam for 200 or more days. All samples produced the desirable black, lustrous oxide film (Fig. 1) and weight gains determined statistically to be significantly lower than the Zircaloy-2 strip samples exposed for comparable time periods in $750^{\circ} \mathrm{F}$ steam.

Based on the findings of the evaluation program, approximately 50, $000 \mathrm{lb}$ of Zircaloy -3 ingots were produced and processed into strip (Ref 1). Chemical analysis indicated that all of the material was acceptable. The strip was then released for machining and subsequent fuel element fabrication. Strip corrosion coupons were submitted concurrently for testing. A considerable number of fuel element components had been processed when these corrosion specimens were examined after a 
14 -day, $750^{\circ} \mathrm{F}$ steam test. The corrosion specimens were found to contain many small discontinuous areas of gray or white corrosion product dispersed in a continuous oxide (Fig. 2). The continuous oxide film was not the usual black lustrous type but was dull and somewhat brownish and the small white areas which appeared were noticeably elongated as stringers in the rolling direction.

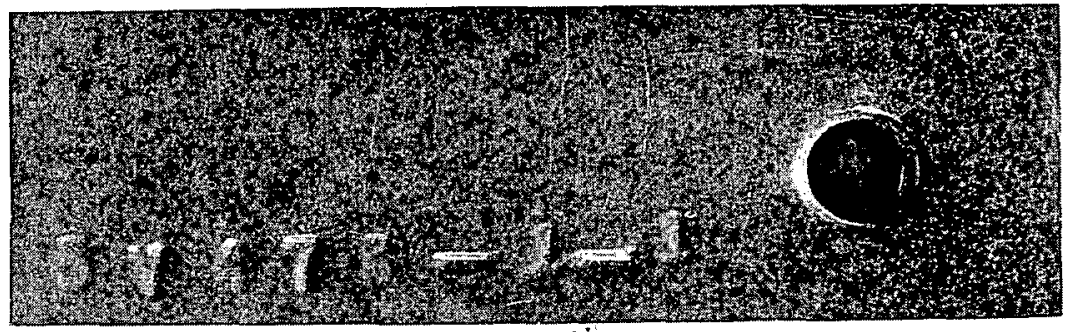

Fig. I Corrosion Tested Zircaloy-2 Sample Showing a Satisfactory Black Lustrous Adherent Oxide Film

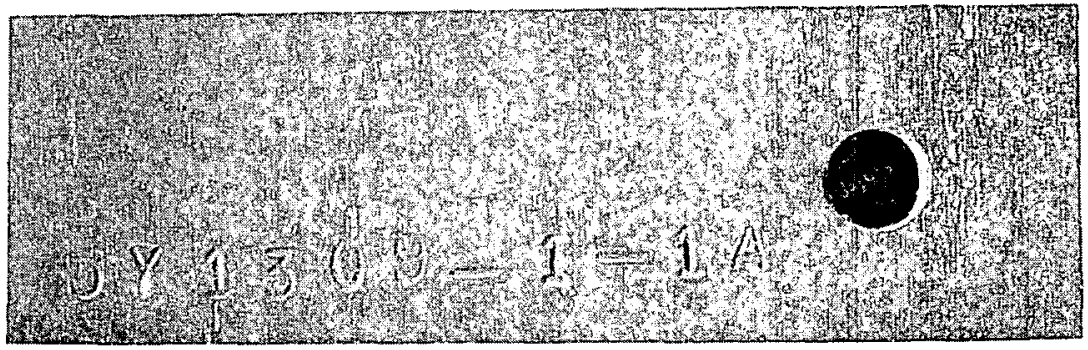

Fig. 2 Corrosion Tested Zircaloy-3 Sample Showing Stringer-Type Corrosion

This type of corrosion behavior had been noted in Zircaloy-2 strip coupons after testing times of several hundred days. However, no special significance was attached to the observation, primarily because the effects had not been observed in the tests performed on the final product, the fuel element. Several fuel elements clad with the Zircaloy-3 strip from each of the ingots that showed this stringer-type corrosion were tested for 14 days in $750^{\circ} \mathrm{F}$ steam. After 3 days, these elements showed a normal corrosion appearance. However, after 14 days, the elements showed a severe stringer-type corrosion product. This type of corrosion had not been previously observed in Zircaloy-3. The amount of stringers present would not be expected to affect heat transfer but there was no information available as to what effect longer exposure times and irradiation would have on the fuel elements. One possibility was that the stringers would continue to grow and would affect the cladding integrity, thereby exposing the fuel alloy to the coolant medium. Another possibility was the flaking of the white oxide and subsequent radioactive contamination of the primary cooling system (Ref. 2).

By the time the Zircaloy-3 stringer corrosion problem was discovered, a large number of fuel elements had been fabricated using the material as cladding. It was decided to use these elements as an experiment to determine whether the presence of stringer corrosion led to any decrease in cladding integrity or to excessive activity in the primary loop. It was decided, in view of urgent schedules, to replace the Zircaloy-3 cladding in subsequent reactors with components from Zircaloy-2. This was done using ingots produced from sponge and atmosphere melting which were assumed to produce the same high quality ingots as those previously used for PWR Core 1. Despite the fact that the strip corrosion coupons passed the standard 14 -day, $750^{\circ} \mathrm{F}$ steam test, fuel elements given the same test showed the presence of faint grayish-white stringers. This was the first well documented case where Zircaloy -2 exhibited white stringers after a $14-$ day, $750^{\circ} \mathrm{F}$ steam test. This condition was identical to that previously found in Zircaloy-3, the differences being principally that, in 
Zircaloy-2, the stringers were considerably smaller in size and more uniformly distributed. Subsequent to these findings, the stringer corrosion problem in Zircaloy-2 increased considerably. As fabrication of ingots continued, the problem became more and more severe and the frequency of stringer occurrence increased tremendously (Ref 1). The seriousness of the problems posed in the corrosion of Zircaloy-3 led to analysis of chemical data, melting history, fabrication history, a review of the Zircaloy-3 development program, metallographic examination, heat treatment studies, and numerous experiments to study the effect of cooling rate. On the basis of the findings of the investigation for Zircaloy-3, similar studies were conducted for Zircaloy-2.

The Zircaloy-2 problem was not apparent until several months of investigating the problem with Zircaloy-3 had passed. The Zircaloy-3 studies provided information as to methods of attack for the Zircaloy-2 problem. In many instances, work was performed concurrently on the two alloys, but an attempt has been made to separate the work described in this report into that for each alloy. This has been done because the stringer-type corrosion of each alloy has been attributed to a different mechanism. Two types of stringers exist in Zircaloy. One type is attributed to gas voids in the ingot and the other is attributed to intermetallic compounds. By virtue of their origin, they are termed gas-void stringers and intermetallic stringers, respectively.

INVESTIGATIONS

$\underline{\text { Zircaloy }-3}$

Chemical Analysis

One of the first steps taken to resolve the stringer-type corrosion problem was to investigate the chemical analyses of all Zircaloy-3 ingots exhibiting poor corrosion resistance and to compare these analyses with those of Zircaloy-3 ingots known to have satisfactory corrosion resistance. In addition, strip samples of a number of Zircaloy-3 ingots were analyzed in an effort to detect chemical differences. Analyses for oxygen, hydrogen, and chlorine from strips which failed in corrosion showed no disparity from the gas content of ordinary strip. No chemical differences were determined from this work (Ref 2). Compilation of sponge blend chemical analyses gave no indications as to the reasons for the poor corrosion behavior of some ingots (Ref 3). It was found in numerous cases that the same blend had been used in different ingots, the strip from one ingot corroded while that from the other did not.

Harp attempted to detect micro-segregation of alloy elements within large as-cast grains. In this work, a section of as-cast Zircaloy-3 was examined with a spectrograph by sparking grain boundaries and the center of grains. Twenty-two areas, each approximately 0.025-in. in diam, were examined. Differences in the grain boundaries and grain centers were not detected. Wet chemical techniques were utilized to determine differences in a large columnar grain. The grain was machined 0.010 -in. on each side of and including the grain boundary in order to obtain a sample. A sample was obtained from the center of the grain in a similar manner. Both samples were analyzed for tin and iron, but no differences were detected between the samples.

\section{Melting History}

- The melting history of all Zircaloy-3 ingots was investigated. A compilation of data was made which included the sponge blends used, the sponge blend chemical analysis, the date the ingot was melted, and the melting vendor. Examination of these data showed no obvious differences between the melting of corrodible and non-corrodible material. Conferences were held with melting vendors and sponge producers to ascertain any changes in practice which might have influenced the corrosion behavior of Zircaloy-3. The melting vendors and sponge producers were not aware of any changes in their practice which might have resulted in adverse effects (Ref 2 ). 
Each of the melting vendors used different power levels for ingot melting, thereby introducing different melting and cooling rates. In addition, the melting rates had increased over the years as a means of increasing production. It was considered possible that the stringer-corrosion problem was the result of areas of micro-segregation which developed during freezing and were strung out during fabrication. These areas could corrode at an accelerated rate. To investigate this possibility, an experiment which involved the melting of three Zircaloy-3 ingots, each at a different rate, was performed (Ref 4). The rates, one above and one below the normal rate, were 7.3, 7.9, and 9.0 $1 \mathrm{~b} / \mathrm{min}$. One-half of each ingot was fabricated using the facilities of a different vendor. Samples taken at each stage of reduction were corrosion tested for 14 days in $750^{\circ} \mathrm{F}, 1500$-psi steam. The corrosion test results showed no significant differences existed among the ingots. The coupons from the 4-in. square billet corroded in a granular and spotty manner, those from the 3/4-in. -thick slab had short stringers, and coupons from the 0.180-in. -thick strip had longer stringers with more distinct evidence of directionality.

An attempt to recover corrodible machined Zircaloy-3 components by remelting was unsuccessful. Approximately $1200 \mathrm{lb}$ of components were tack-welded into a consumable electrode and remelted into two, 600-1b ingots. One ingot was melted in an argon atmosphere and the other in a dynamic vacuum. Both ingots were forged and hot rolled to strip. Samples from slab and strip, representing top, middle, and bottom of the ingots, were taken for corrosion testing. After a $14-\mathrm{day}, 750^{\circ} \mathrm{F}$, 1500 -psi steam test, the specimens showed normal weight gains. Upon metallographic examination, it was observed that the strip from the argon-melted ingot contained both void-type and intermetallic stringers, whereas the strip from the vacuum-melted ingot contained stringers which were primarily of the intermetallic type. Pronounced banding of the intermetallic stringers was apparent for all coupons. Two significant conclusions were drawn from this work: (1) Remelting neither eliminates nor minimizes stringer-type corrosion in Zircaloy-3; and (2) affirmed the conclusion that stringers in Zircaloy - 3 are primarily intermetallic stringers which cannot be eliminated by vacuum-melting. (The latter conclusion is discussed in detail in a subsequent section entitled, "Metallographic Examination and Heat Treatment Studies").

\section{Fabrication History}

An attempt to reconstruct the complete fabrication history for each ingot was impossible because of inadequate records and because recording of information was performed only to indicate that the existing specification had been met (Ref 2 ). The records available seemed to indicate that forged material had better corrosion resistance than bloomed material. Several ingots were halved and fabricated to strip by either blooming or forging. The results of corrosion tests of the strip gave no indication that one fabrication technique was superior to the other.

\section{Zircaloy-3 Development Program History}

The reports of the original Zircaloy-3 development program were scrutinized in an effort to detect differences between the practices used at that time and those employed during the period in which the non-corrosion resistant material was produced. Nothing of any consequence was determined (Ref 2). Samples of the material melted as part of the original program were retested and found to be corrosion resistant as reported.

\section{Corrosion Testing}

One of the early suspicions concerning the stringer-type corrosion of Zircaloy-3 strip was that the ingots contained micro-porosity which did not heal and which was elongated during strip fabrication. During machining, these voids were opened and when the strip was pickled for corrosion testing, some of the acid was entrapped in the voids by capillary action. The entrapped acid caused the accelerated corrosion noted. Work by Kass, Fontanese, and Oaks (Refs 5 and 6) in which special rinsing techniques, special etching, abrasion, and in particular, special machining with no etching 
prior to corrosion testing demonstrated that acid entrapment was not the cause of stringer-type corrosion. Even when etching was not employed, stringer-type corrosion was found.

One difficulty encountered in the study of stringer-type corrosion was the long waiting period (about three weeks) needed to obtain the results of a two-week corrosion test. Cochrun developed a short-time test that usually gave Zircaloy a surface appearance that corresponded to that of specimens corrosion tested for 14 days in $750^{\circ} \mathrm{F}$ steam. The specimens which had been prepared as corrosion specimens were heated in an electric annealing furnace with ambient atmosphere for $100 \mathrm{~min}$ at $1100^{\circ} \mathrm{F}$. This test was utilized for quick indications of the effects of various heat treatments on reducing stringer-corrosion. Final judgement, however, was made only after the complete 14-day, $750^{\circ} \mathrm{F}$ steam test.

Metallographic Examination and Heat Treatment Studies

The basic difference noted in a comparison of the microstructures of corrodible and non-corrodible Zircaloy-3 strip was that those samples which corroded most severely had a dense, continuous grain-boundary precipitate. Such behavior, only on a reduced scale, had previously been related to the cooling rate in Zircaloy -2 by Carver and Hayes (Ref 7). Because of the microstructural differences noted, the major effort of the investigation was directed toward producing a Zircaloy-3 microstructure which would yield corrosion resistant strip.

Zirconium is an allotropic element and the dilute alloys such as Zircaloy-2 and -3 exhibit the structural changes of the base metal. The solubility of the alloying elements and the impurity elements in the base metal vary considerably, depending upon the temperature. Therefore, it is possible to alter the microstructure of these alloys by heat treatment.

Microstructural stringers had been noted in Zircaloy-2 strip products for several years, and numerous investigations had been performed to determine their nature. Opinion was divided as to whether the stringers in Zircaloy-2 were a second phase or a void. Extensive examination of innumerable Zircaloy-3 samples convincingly illustrated that the majority of stringers were not voids but were a second phase. However, some of the stringers exhibited discontinuities which were apparently highly polished hemispherical voids. It was not ascertained immediately whether these structures result from removal of the second phase during polishing and etching operations or if they represented a void, formed during melting, elongated during fabrication. The major portion of the stringers was composed of a dark etching material which was assumed to have been strung out during fabrication. The nature of the stringers' corrosion behavior strongly indicated that the microstructural stringers were directly associated with the corrosion stringers.

During the many previous metallographic examinations of Zircaloy-2, it had been observed that stringers were present (Ref 8 ). Thermal treatment of the alloy to remove stringers for improved fabricability had been conducted by M. L. Picklesimer (Ref 9) of the Oak Ridge National Laboratory. He reported that a high-temperature (beta phase) heat treatment was effective in removing the stringers and, hence, in improving the bendability and impact properties of the alloy.

Based on the reported effectiveness of heat treatment to alter the microstructure, a concentrated effort was made to determine the effect of heat treatment on the corrosion resistance of corrodible strip. A group of Zircaloy-3 samples was obtained and heat treated at $1832^{\circ} \mathrm{F}\left(1000^{\circ} \mathrm{C}\right)$ for $24 \mathrm{hr}$ in a dynamic vacuum. After a 14 -day, $750^{\circ} \mathrm{F}, 1500$-psi steam test, these samples exhibited a black lustrous oxide film and were devoid of stringer corrosion (Ref 3). The samples were tested for a total of 42 days in $750^{\circ} \mathrm{F}$ steam and continued to show excellent corrosion resistance. Metallographic examination showed a drastic change in microstructure. It became immediately evident that the solution of the second phase constituents at the elevated temperature and their redistribution was the reason for the noted improvement in corrosion resistance. Experiments were initiated to determine the optimum time-temperature combination for maximum corrosion resistance. Samples of Zircaloy-3 
strip from several ingots known to exhibit stringer-type corrosion were heated for $1 / 2,2,4$, and $8 \mathrm{hr}$ at $1500^{\circ}, 1600^{\circ}, 1700^{\circ}$, and $1800^{\circ} \mathrm{F}$ in argon-filled Vycor bulbs (Ref 3). The samples were corrosion tested for 14 days in $750^{\circ} \mathrm{F}$ steam. It was found that the $1700^{\circ} \mathrm{F}$ and $1800^{\circ} \mathrm{F}$ treatments improved the corrosion appearance. However, the greatest improvement was found in the samples heated at $1800^{\circ} \mathrm{F}$. for 4 and $8 \mathrm{hr}$. It was decided that the homogenization heat treatment would best be performed at $1800^{\circ} \mathrm{F}$ for $8 \mathrm{hr}$. The $1500^{\circ} \mathrm{F}$ and $1600^{\circ} \mathrm{F}$ heat treatments did not noticeably improve the corrosion appearance of the Zircaloy -3. Once the parameters of an optimum homogenization treatment had been established, it was thought that the increased homogeneity of the Zircaloy -3 caused by dissolution of the microstructural stringers (believed responsible for the corrosion stringers) would result in a more uniform corrosion film. Thus, a decrease in the standard deviation of the corrosion test weight gain of homogenized Zircaloy-3 as compared to non-homogenized Zircaloy-3 would result. However, it was shown that the corrosion resistance of the homogenized material was significantly less than that of the non-homogenized Zircaloy-3, while the standard deviation did not differ significantly. The subsequent cooling rate work showed this approach to be fallacious since the heat treatment used in preparing the homogenized material employed a slow furnace cool.

Microstructural examination of longitudinal sections of Zircaloy-3 strip, exhibiting stringertype corrosion, did not show stringers such as those seen in and commonly associated with the microstructure of Zircaloy-2 strip. Similar examination of the rolling plane showed banding of precipitate in the direction of rolling (Refs 10 and 11). (See Figs. 3 and 4.) This type of structure has not been

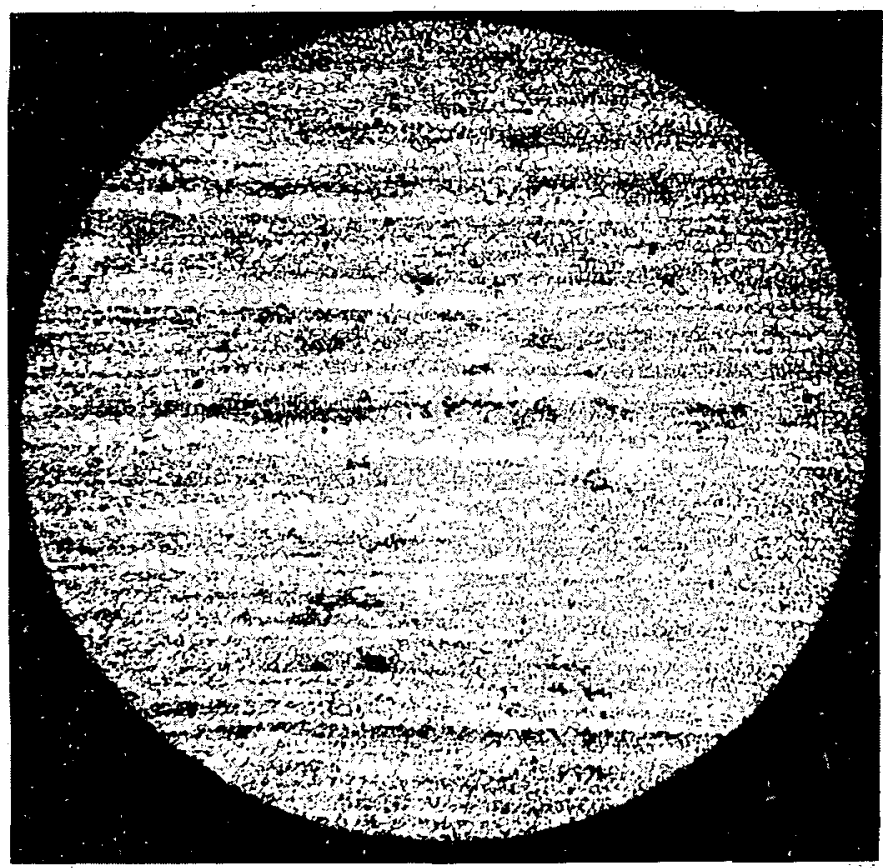

Fig. 3 Zircaloy Strip from Ingot 5 Yll 28 Heat Treated at $1500^{\circ} \mathrm{F}$ for $8 \mathrm{Hr}$ in an Argon-Filled Vycor Bulb; Air Cooled; Rolling Flane View; $25 x$ observed in Zircaloy-2. A relationship between the banding in the microstructure and the stringer-type corrosion was apparent, although it has not been possible to determine if the corroding stringer-type oxide forms over an area of precipitate or over an adjacent area depleted in the elements forming the precipitate. Examination of the phase diagrams for the $\mathrm{Zr}-\mathrm{Sn}$ and $\mathrm{Zr}-\mathrm{Fe}$ systems indicated that the precipitate was primarily $\mathrm{ZrFe}_{2}$. Attempts to verify this by $\mathrm{X}$-ray techniques were unsuccessful. The possibility that dissolution of the precipitate in the matrix by heat treatment would improve corrosion resist arice was explored. Samples were heat treated at temperatures from $1400^{\circ} \mathrm{F}$ to $2000^{\circ} \mathrm{F}$ at times from $15 \mathrm{~min}$ to $72 \mathrm{hr}$. On the basis of this work and subsequent corrosion testing, it was found that $8 \mathrm{hr}$ and $1800^{\circ} \mathrm{F}$ were the shortest time and lowest temperature that consistently eliminated stringer-type corrosion in Zircaloy-3.

To investigate further, the homogenization treatment, a group of ten machined Zircaloy-3 cladding components was heat treated in a static vacuum; five were treated at $1700^{\circ} \mathrm{F}$ for $8 \mathrm{hr}$ and five were treated at $1800^{\circ} \mathrm{F}$ for $8 \mathrm{hr}$. Samples from each heat treatment were corrosion tested and the previous results were confirmed; the corrosion stringers were eliminated and the components heated at $1800^{\circ} \mathrm{F}$ showed the most improvement. 


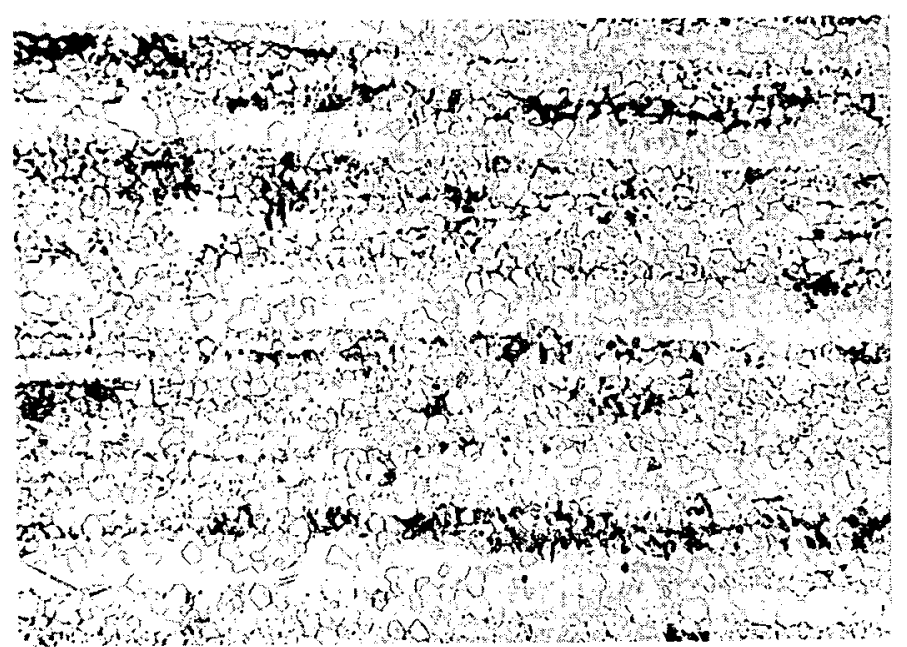

Fig. 4 Zircaloy-3 Strip from Ingot $5 \% 1128$ Heat Treated at $1500^{\circ} \mathrm{F}$ for $8 \mathrm{Hr}$ in an Argon-Filled Vycor Bulb; Air Cooled; Rolling Plane View; $50 x$
At about this time (January 1957), the first evidence of a similar corrosion effect in Zircaloy -2 became apparent. Strip from two Zircaloy- 2 ingots showed stringer-type corrosion after a 14 -day, $750^{\circ} \mathrm{F}$ steam test. Microstructural examination did not show any outstanding differences between corrodible and corrosion-resistant strip. It was felt that the problem was similar to that of Zircaloy-3. Therefore, an experiment to investigate methods for improving the corrosion resistance of Zircaloy -2 was initiated. The results of this work are presented later.

\section{Commercial Homogenization}

On the basis that all of 87 different

Zircaloy-3 samples responded to the $1800^{\circ} \mathrm{F}$,

8-hr homogenizing heat treatment, it was decided to homogenize all production Zircaloy-3. Although the beneficial response of Zircaloy-2 to homogenization had not been accurately determined, it was decided, based on prior metallurgical knowledge, that the homogenization would not be expected to impair the corrosion resistance of Zircaloy-2 and, therefore, all production Zircaloy-2 should likewise be homogenized.

It is preferable to heat zirconium and its alloys in vacuo, but because commercial vacuum facilities were either not large enough or could not maintain the required temperature for an extended time, it became necessary to homogenize the production material in an argon atmosphere. A carbottom type furnace utilizing a steel retort with a sand seal was employed. A positive argon pressure was maintained during the homogenization. The possibility of a furnace leak and subsequent contamination and the possibility of grain growth during the heat treatment and its subsequent effect on the fuel during cladding operations were the two main factors in the decision to homogenize the Zircaloy in an intermediate 1/2- to 3/4-in. -thick slab form rather than as strip. It was felt that if the slabs were contaminated, the layer of contamination would be made thin during subsequent rolling operations and would be eliminated during later machining operations, and that any large grain size in the slabs would be eliminated by subsequent rolling operations.

On the basis of the laboratory findings, it was decided to homogenize the Zircaloy-3 machined components as well as the material in the process of being fabricated. Machined components were heat treated in vacuum facilities available at Bettis, whereas, 3/4-in. and 1/2-in. slabs were homogenized in a large furnace filled with inert-gas. Difficulties were experienced during the heat treatment at each of the facilities. At Bettis, the furnace temperature dropped about $250 \mathrm{~F}^{\circ}$ as a result of a fault in the controller. The furnace was returned to temperature and the heat treatment completed. However, when the machined plates were removed from the furnace, they were badly distorted. Their appearance was that of hammered aluminum tableware. This effect of thermal cycling through the transformation had been observed by others (Ref 12) but it was not thought to be so severe that only one cycle would render the components as useless as in this instance. Fuel elements manufactured from correctly homogenized cladding components were not as uniform as those produced from non-homogenized components. In some cases the fuel ends distorted, while in others the element surfaces exhibited large grains. In general, the homogenized cladding components had poor deformation characteristics. [Note: Work beyond the scope of this paper has shown that beta heat treatments reduce the ductility of Zircaloy -2 and -3 (Refs 13, 14, and 15)] . 
Charges of several thousand pounds of $1 / 2$-in. and 3/4-in. slabs were introduced. . The first charge to be homogenized consisted of material from twelve Zircaloy-3 ingots and one Zircaloy-2 ingot; the second charge consisted of material from fourteen $Z$ ircaloy- 2 ingots. The heat treatments were performed without incident. Samples representing each ingot as slab and as strip, both before and after homogenization, were corrosion tested in $750^{\circ} \mathrm{F}$ steam for seven days.

The results of the corrosion test showed that in each case the corrosion resistance (as measured by weight gain and appearance) of the slabs and strip had been impaired by the homogenization treatment. The severity of the corrosion in the homogenized strip: appeared to be directly related to the corrosion appearance of the corresponding homogenized slab. It was also noted that the stringer appearance was eliminated and that the homogenized strip corroded in discrete spots instead (Ref 3 ).

At first it was thought that the slabs had been excessively contaminated during homogenization. Calculations of the amount of nitrogen and oxygen pickup caused by diffusion from the atmosphere indicated it was possible to contaminate a 3/4-in. slab significantly if it were heated in an improper atmosphere. It was concluded that nitrogen contamination (to a degree sufficient to impair corrosion resistance) was possible, but in the actual homogenization carried out in an argon atmosphere it is unlikely that the contamination indicated by the calculations would occur (Ref 16). Chemical analyses made to detect nitrogen and hydrogen pickup showed normal contents for both elements. At the same time that the contamination of the homogenized Zircaloy was being investigated, microstructural studies were initiated. Ordinarily, the laboratory homogenized specimens exhibited a Widmanstattentype structure and very little precipitate after homogenization. However, the homogenized slab samples showed large equiaxed grains surrounded by a second phase. It was quite obvious that the large masses of metal cooled far more slowly after commercial homogenization than did any of the laboratory specimens.

Microstructural evidence and the results of work previously undertaken to explore the effects of cooling rates as a result of the homogenizing temperature verified the assumption that the large mass of the slabs gave cooling rates which permitted the alloying elements to precipitate and segretate in the grain boundaries. About a month prior to this development, a study was begun on the effect of cooling rates after homogenization. Ultimately, this work proved quite valuable in verifying the fact that the cooling rate after homogenization is extremely important. To corroborate these findings on a commercial scale, approximately $300 \mathrm{lb}$ of the Zircaloy-3.previously homogenized at the Westinghouse Blairsville Metals Plant and subsequently fabricated to strip was rehomogenized. An innovation was introduced at this time; the retort was flushed with refrigerated helium in order to accelerate cooling. After corrosion testing for 3 days in $750^{\circ} \mathrm{F}$ steam, the material exhibited the black lustrous corrosion film of acceptable material; no stringers were noted. An important point was noted at the time; the warping effect previously observed when Zircaloy was cycled through the beta region was absent. This was attributed to the intervening hot rolling when the slab was reduced to strip.

To determine the effect of a high alpha anneal, corrosion tested coupons from both the homogenized and non-homogenized conditions were reprepared by vapor blasting and pickling and subjected to $4 \mathrm{hr}$ at $1500^{\circ} \mathrm{F}$ in vacuo. Subsequent analysis of $14-$ day, $7.50^{\circ} \mathrm{F}$ steam test data revealed a signif-icant improvement in both the homogenized and non-homogenized Zircaloy-3 after annealing, the analysis also showed the existence of a first order interaction between homogenization and annealing in which the anneal cancelled the detrimental effect of homogenization. These results intensified the efforts to determine the temperatures, times, and cooling rates which controlled the corrosion resistance of Zircaloy -3 .

Cooling Rate Studies

Experiments to determine what effect the cooling rate following the homogenization treatment had 
on the corrosion resistance had been underway, but the results were unknown at the time the commercial homogenization of Zircaloy slabs was performed (Ref 3). The cooling rate studies were expedited once their paramount importance was predicted.

Experimental heat treatment studies showed that high cooling rates, such as those obtained in air cooling thin specimens, resulted in corrosion resistant Zircaloy-3, whereas, furnace cooling of these specimens impaired the corrosion resistance (Ref 4). The corrosion behavior was related to microstructure. The microstructure of rapidly-cooled Zircaloy-3 was found to be relatively free of precipitate because the alloying elements were put in solution during the beta heat treatment and retained in solution by the rapid cool. In contrast, the microstructure of slowly-cooled Zircaloy-3 exhibited large quantities of grain boundary precipitate (Ref 17). The slow cool from the beta phase permitted the alloying elements to precipitate because, as the temperature decreased, the solubility of the alloying elements also decreased. Attempts to determine if the areas corroding white were areas of precipitate (enriched in alloying elements) or areas depleted in alloying elements were unsuccessful because the white oxide covered such large areas that it was not possible to determine the exact location with relation to the microstructure.
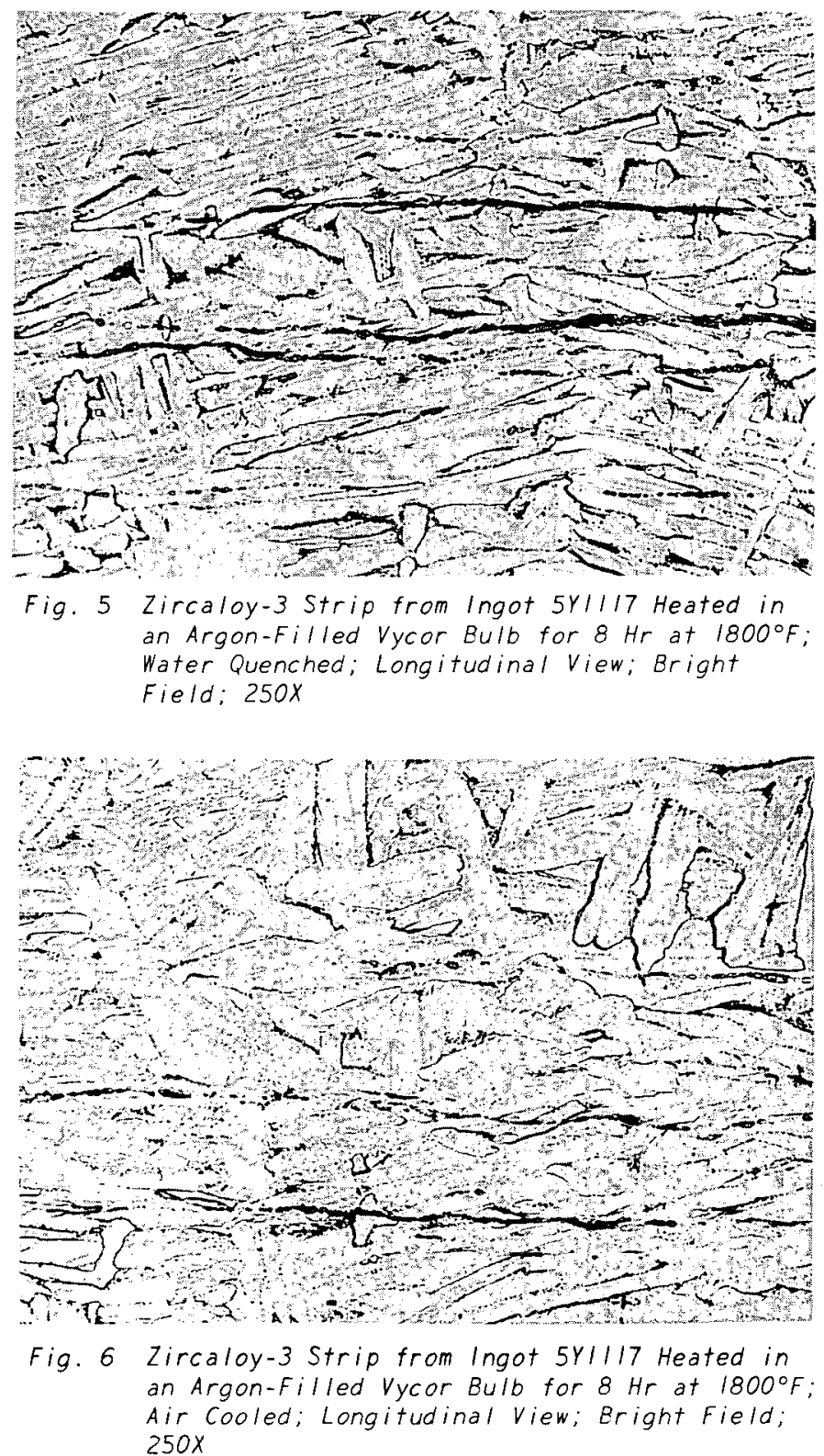

Photomicrographs, such as those in Figs. 5 through 7 , offer the most striking evidence of the effect of cooling rate. Figures 5 and 6 , which represent waterquenched and air-cooled specimens, respectively, illustrate the Widmanstatten-type microstructure typical of rapidly cooled Zircaloy-3. Figure 7 illustrates the type of microstructure obtained by furnace cooling Zircaloy-3 at a rate of $\sim 200 \mathrm{~F}^{\circ} / \mathrm{hr}$.

It was noted that the quantity of grain boundary precipitate increased with decreasing cooling rate. The microstructures of the water-cooled and air-cooled samples were similar in that they contained very little second phase precipitate, whereas, the microstructure of the slow-cooled sample exhibited copious grain boundary precipitate. The results of a 14-day, $750^{\circ} \mathrm{F}$ steam test on samples cooled as described demonstrated that the slow-cooled samples not only exhibited white corrosion product, but also had weight gains approximately 150\% greater than samples cooled rapidly. The rapidly cooled samples showed some white spots and weight gains from 23 to $27 \mathrm{mg} / \mathrm{dm}^{2}$. The acceptable weight gain is specified as $28 \neq 10 \mathrm{mg} / \mathrm{dm}^{2}$. The white spots noted may have been caused by anisotropic oxidation of different grains or may have been related to the black spots of second phase shown in Figs. 7 and 8 . A similar experiment was performed using 


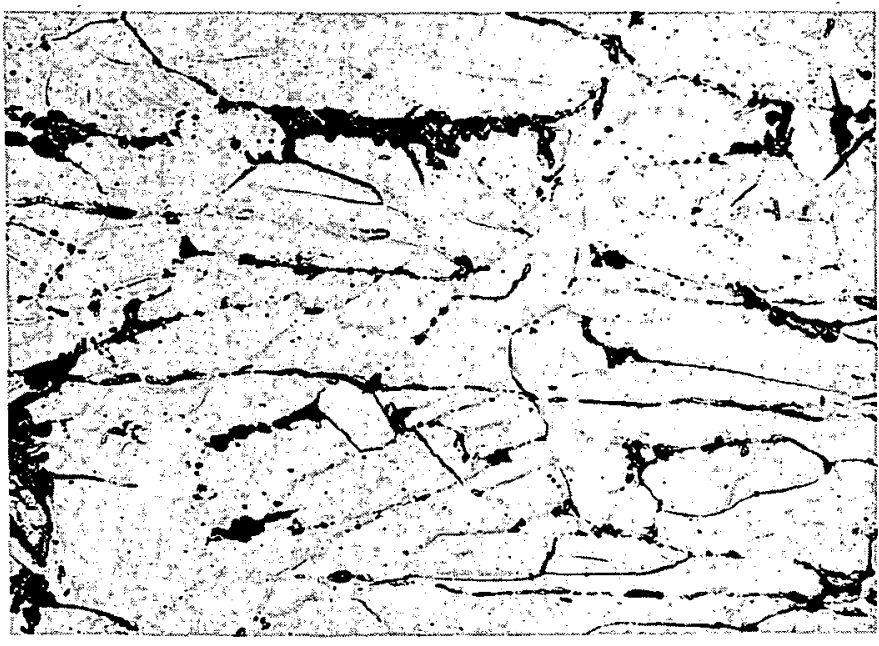

Fig. 7 Zircaloy-3 Strip from Ingot $5 y / 117$ Heated in an Argon-Filled Vycor Bulb for $8 \mathrm{Hr}$ at $1800^{\circ} \mathrm{F}$, Furnace Cooled; Longitudinal View: Bright Field: $250 x$

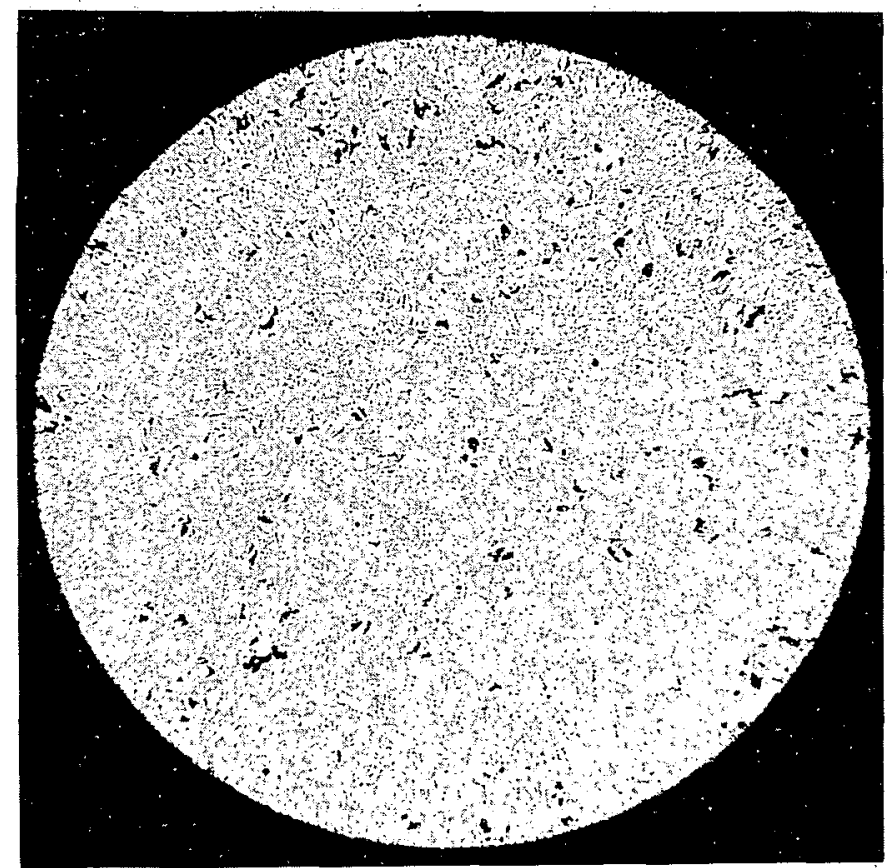

Fig. 8 Zircaloy-3 Strip from Ingot $5 y / 128$ Heat Treated at $1800^{\circ} \mathrm{F}$ for $8 \mathrm{Hr}$ in Argon-Filled Vycor Bulb: Air Cooled; Rolling Plane View; Bright Field; $25 x$
Zircaloy-2: The effect of cooling rate on the microstructure and corrosion resistance was just as impressive for Zircaloy-2 as it was for Zircaloy-3 (Ref 17).

Zircaloy-2

\section{Corrosion Problem}

During the spring of 1957, the sched. ular requirements for nuclear cores were so urgent that it was decided to replace all Zircaloy- 3 cladding with Zircaloy -2 and to concentrate on efforts to salvage the Zircaloy -3 components by suitable heat treatment. The replacement Zircaloy- 2 was expected to be of the same high quality as that used for PWR Core 1. Although strip coupons passed the 14 -day, $750^{\circ} \mathrm{F}$, 1500 psi acceptance test, fuel elements fabricated from the strip exhibited faint, grayish-white stringers when subjected to the same test. The corrosion appearance was similar to that of Zircaloy-3 except that the stringers were smaller in size and more uniformly distributed (Ref 1).

Before long, the number of Zircaloy-2 ingots so affected rose sharply as did the severity of the stringer-type corrosion. Since Zircaloy- 2 was to be used for the cladding in all reactors built at Bettis, salvaging of Zircaloy-3 was halted and all efforts were directed to the solution of the Zircaloy- 2 corrosion problem. Fortunately, because of the Zircaloy-3 problem, avenues of investigation had already been opened. These consisted of a review of chemical and corrosion records, metallographic examination, heat treatment, and cooling rates.

\section{Statistical Analysis of Bettis Records}

Bettis records relating to chemical

analysis, sponge producer, melting vendor, type of melting, and corrosion weight gain of Zircaloy-2 were subjected to statistical analysis with the hope that the analysis would shed some light on the cause of the stringer-type corrosion. Members of the Bettis Statistical Staff and J. Wahler of Olin Mathieson Chemical Corporation reviewed the data. Wahler was able to detect differencës in several areas, büt the differences were not usable in identifying the source of the stringer corrosion. Bettis statisticians found the data incomplete in spots or unusable, as for example, chemical datä reported as "less than." The great effort expended in analyzing past data did not aid materially in the solution 
of the stringer corrosion problem, but it showed areas in which better records should be maintained, indicated better ways to keep the records, and pointed out areas for further investigation.

Fabrication Studies

The commercial fabrication of Zircaloy-2 is performed by forging at $1800^{\circ} \mathrm{F}$ and rolling at $1550^{\circ} \mathrm{F}$. These temperatures are utilized because they permit easy fabrication of the alloy and because the resultant product is corrosion resistant. No particular attention was given the phases present in Zircaloy-2 during fabrication until Picklesimer and Adamson of ORNL (Ref 9) studied methods to obtain isotropic mechanical properties and to minimize stringer formation. They postulated that stringers were intermetallic compounds formed during fabrication in the two-phase field because of the differential solubility of the alpha and beta phases for the alloying elements (particularly iron, chromium, and nickel). These elements have a high solubility in the beta phase and limited solubility in the alpha phase. During two-phase fabrication, they diffuse to areas of the beta phase which become elongated in the direction of rolling. When cooled to between $1418^{\circ} \mathrm{F}$ and $1445^{\circ} \mathrm{F}$, the areas of beta transform to alpha (Ref 18), the solubility decreases, and these elements precipitate as compounds and are observed as stringers in the elongated areas of prior beta. Picklesimer and Adamson reported that stringers could be eliminated by beta-phase heat treatments to dissolve the precipitate followed by a quench to prevent their reprecipitation. Based on this laboratory work, they recommended a fabrication procedure which avoided the two-phase field during forging and rolling, after which the material was given a beta-phase heat treatment followed by a quench. Subsequently, the material was cold or warm rolled (less than $500^{\circ} \mathrm{C}$ ) with not less than $20 \%$ reduction and annealed at $800^{\circ} \mathrm{C}$ or less for 15 to $30 \mathrm{~min}$.

Picklesimer later reported that utilization of this procedure on a commercial basis was not successful in eliminating stringers (Ref 4). * Bettis laboratory comparisons of the old procedure with the recommended one showed no significant differences in the corrosion results of the two methods (Ref 4). Several ingots were fabricated by different vendors to see if any corrosion disparities could be noted; none was found. Because the basic fabrication procedure had not been altered since 1952, it was apparent that fabrication was not the cause of stringer-type corrosion in Zircaloy-3.

To determine the origin of microstructural stringers in Zircaloy-2, a fabrication experiment (Refs 19 and 20) was designed to show whether or not microstructural stringers were a result of ingot porosity and whether or not they could be eliminated by a homogenization heat treatment. Vacuummelted ingot FZ-237 and atmosphere-melted ingot FZ-625 were selected for this study. Two samples, $8 \times 1-1 / 2 \times 1-3 / 4$ in. , were selected from the top 6-in. section of both ingots to ensure that a maximum amount of porosity would be present in the samples. Examination of macro-etched sections of these two samples showed that the porosity in both samples was uniform and that the atmospheremelted ingot exhibited far greater porosity than the vacuum-melted ingot sample. Each sample was hot rolled to a thickness of 3/4 in. One-inch sections were then cut off the ends of the hot-rolled samples and prepared for metallographic examination. This procedure was followed for subsequent reductions to $1 / 2-, 1 / 4-$, and 1/8-in. strip. Examination of the samples from the successive steps during rolling showed that ingot voids, shown in Fig. 9, were flattened out and elongated into a gasvoid stringer as shown in Fig. 10. Fewer and smaller gas-void stringers were found in the vacuummelted sample than in the atmosphere-melted sample.

Samples of the 1/8-in. hot-rolled strip were homogenized at $1850^{\circ} \mathrm{F}$ for 4 hr in a helium atmosphere and air quenched. Although the as-rolled grain structure was altered during this heat treatment, gas-void stringers still were apparent in both materials, as shown in Fig. 11.

From this study (Ref 20) and that of Picklesimer (Ref 8) it was concluded that the majority of stringers in Zircaloy-2 hot-rolled strip are a product of ingot porosity and that fewer and smaller

\footnotetext{
* M. L. Picklesimer, Oak Ridge National Laboratory, Private Communication
} 


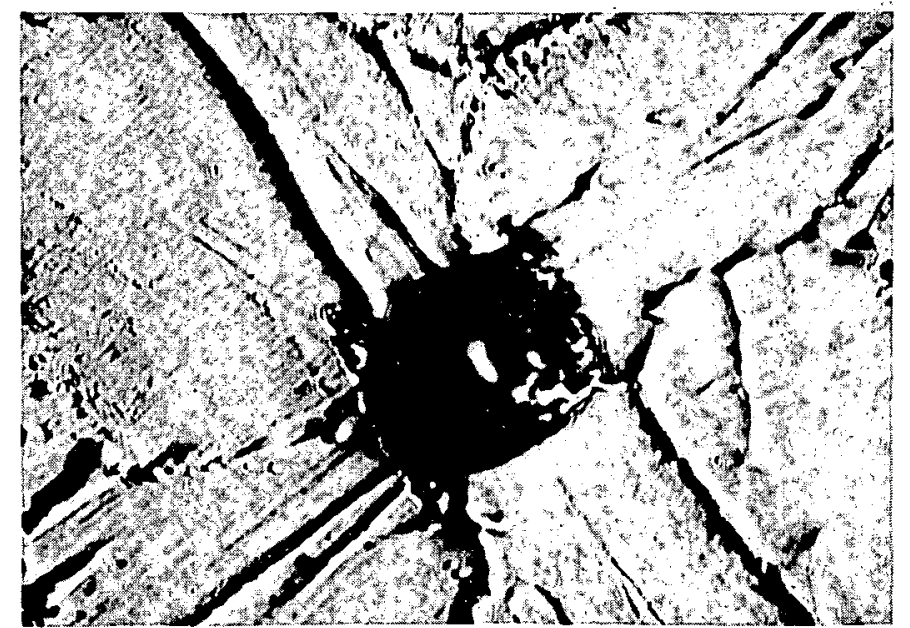

Fig. 9 Atmosphere-Melted Zircaloy-2, As-Cast Ingot Structure Showing Void; As-Etched; Oblique Lighting; $1000 x$

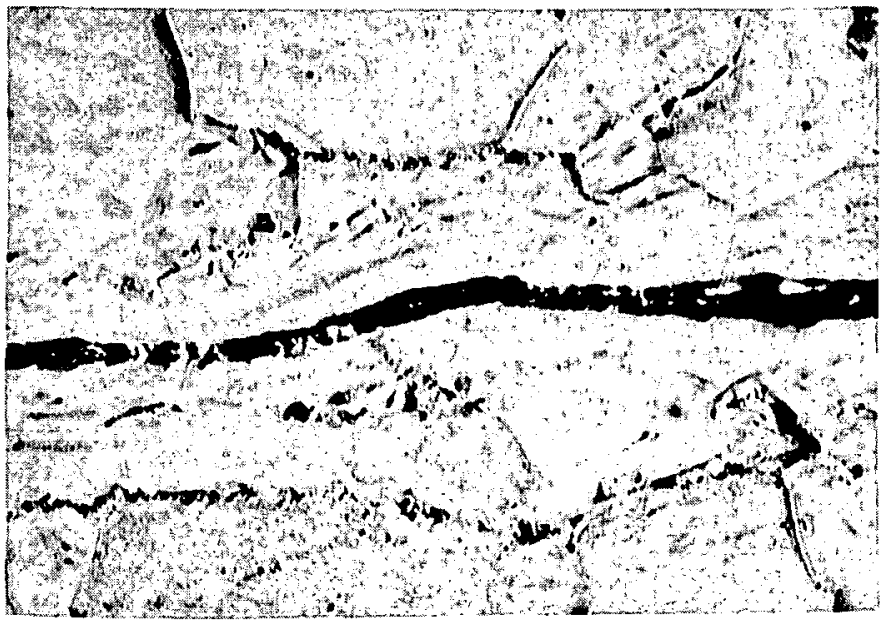

Fig. 10 Vacuum-Melted Zircaloy-2 Hot Rolled to 1/8-in. Strip: Longitudinal View; As-Etched; Oblique Lighting: 1000x

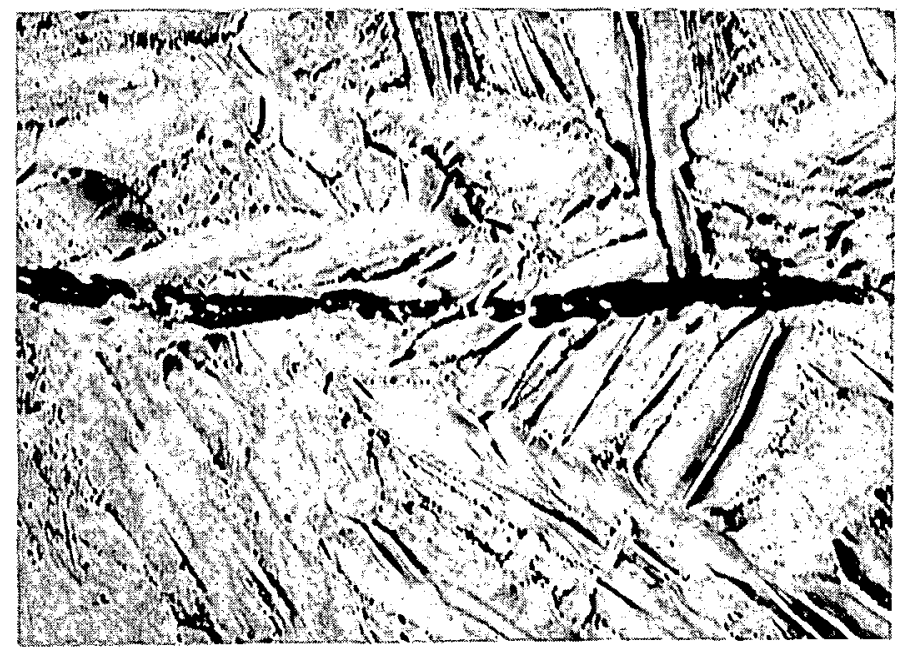

Fig. II Homogenized Zircaloy-2, Hot-Rolled Strip: Gas-Void Stringer Remains after Heat Treatment; As-Etched; Oblique Lighting; $1000 x$ ğâs-void stringers are found in hot-rolled strip made from vacuum-melted ingot than in strip made from atmosphere-melted ingot.

\section{Metallographic Examination and Heat}

\section{Treatment Studies}

Work by Carver and Hayes (Ref 7) at the Bureau of Mines (Albany, Oregon) demonstrated the relationship of the microstructure of Zircaloy- 2 to its corrosion resistance. They found that when the precipitate was dispersed throughout the grains as a result of quenching from $1832^{\circ} \mathrm{F}$, the relative corrosion resistance was good, whereas, when the precipitate was concentrated in the grain boundaries as a result of slow cooling from $1832^{\circ} \mathrm{F}$, the relative corrosion resistance was poorest.

Previous work at Bettis on Zircaloy - 3 (described in preceding sections of this report) showed that corrosion resistance of corrodible Zircaloy- 3 could be improved by quenching from the beta phase or impaired by slow cooling from the beta phase. Because of the previous work on Zircaloy-3, heat treatments were immediately employed in an attempt to solve the Zircaloy-2 problem. Time and temperature studies were initiated to determine their effect on corrosion resist ance. This work showed that Zircaloy- 2 had behavior similar to Zircaloy-3 with respect to its heat treatability (Ref 17). Metallographic observation showed that Zircaloy-2 was not completely transformed to beta at $1800^{\circ} \mathrm{F}$ (to obtain an all beta structure during homogenization, the heat treating temperature was elevated to $1850^{\circ} \mathrm{F}$ ). The cooling rate was found to have the same effect on the corrosion resistance of Zircalloy- 2 as on Zircaloy-3. Microstructural observations on heat-treated Zircaloy-2 demonstrated that it did not undergo such striking changes as did Zircaloy-3. However, the changes observed were such that one could predict the corrosion results from the metallographic appearance with reasonable accuracy. Structures exhibiting appreciable quantities of grain boundary precipitate evidenced higher weight gains than did those which showed a 
fine precipitate uniformly distributed throughout the structure. The relationship of the corrosion resistance and microstructural appearance of the heat-treated Zircaloy-2 is similar to that of Zircaloy-3. The fact that Zircaloy-2 contains less precipitate is due to the broadening of the alpha solubility limit by the larger amount of tin present (1.45\% Sn in Zircaloy-2 vs $0.25 \%$ in Zircaloy-3).

One major difference noted between the microstructure of Zircaloy-2 and Zircaloy-3 was the presence of abundant void-type stringers in the longitudinal direction for Zircaloy-2 and of relatively few in Zircaloy-3. Examination of the surface normal to the rolling plane showed little evidence of void-type stringers in either Zircaloy-2 or -3. However, the Zircaloy-3 showed evidence of stringers composed of precipitate (Ref 17). These differences in microstructure led to the conclusion that although the stringer-type corrosion of Zircaloy-2 and Zircaloy-3 appeared to be similar, it was caused by a different mechanism in each case. Stringer corrosion in Zircaloy-2 was investigated by outlining several longitudinal void-type stringers with hardness indentations and corrosion testing.

A study similar to that performed by Goodwin (Ref 3) was performed by Grozier (Ref 11) on Zircaloy-2 hot-rolled strip. Longitudinal and rolling plane surfaces of a section of hot-rolled strip, made from ingot FZ-614, were polished and etched. On these two surfaces, stringers were outlined with a sharp scribe and photographed. This sample was tested for 14 days in $750^{\circ} \mathrm{F}$ steam. After corrosion testing, the same areas were again photographed. Figures 12 and 13 show the longitudinal view of this sample (400X) before and after corrosion testing. White corrosion product was found to form over the outlined microstructural stringer in both the longitudinal and rolling plane surfaces.

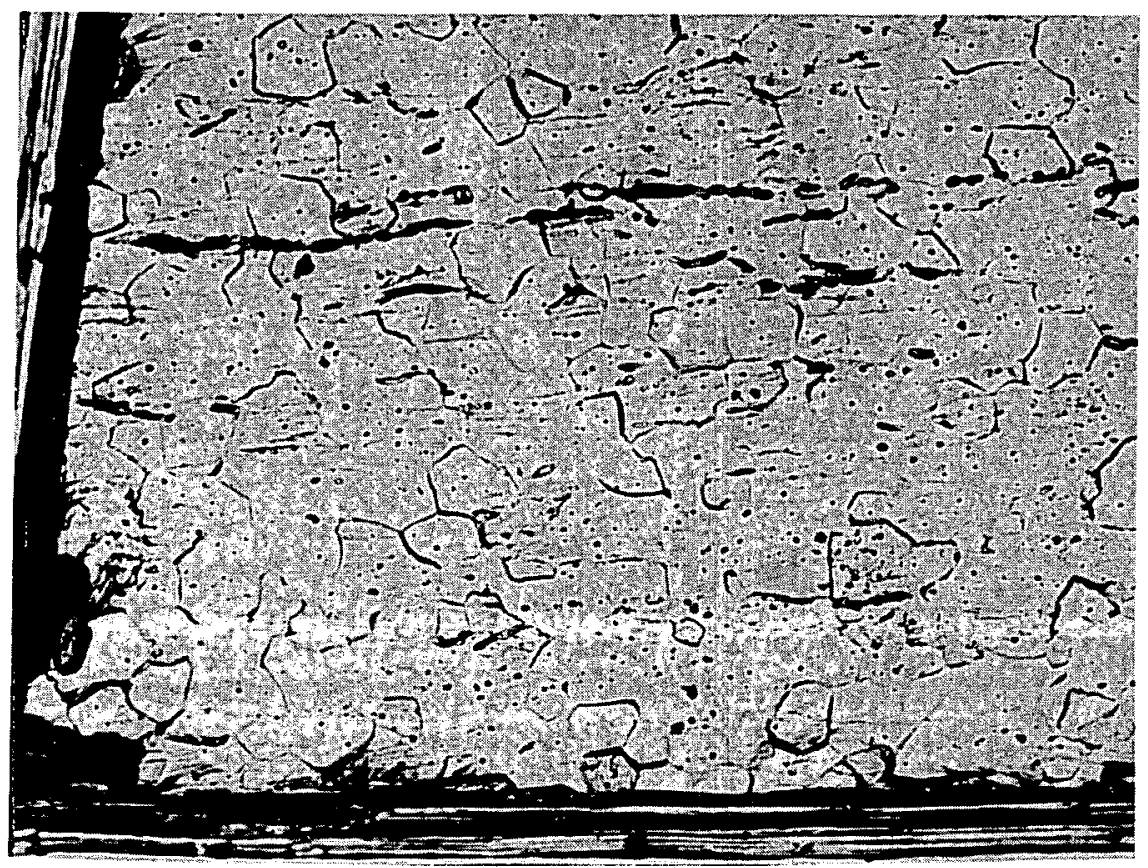

Fig. 12 Longitudinal View of Gas-Void Stringers in Hot-Rolled Strip from Ingot FZ-6/4-2. The Narked Area Shows Appearance of a Stringer before Corrosion Testing: Bright Field: As-Etched; $400 x$

To determine the effect of cooling rate on this relationship between microstructural stringers and corrosion stringers, this same experiment was performed on a similar corrosion coupon that had been water quenched from $1850^{\circ} \mathrm{F}$. No stringer corrosion was evident on this microstructural stringer.

Irradiation Penetration and Stringer Geometry Studies

To evaluate the threat of stringers to cladding integrity, four possible methods of penetration 


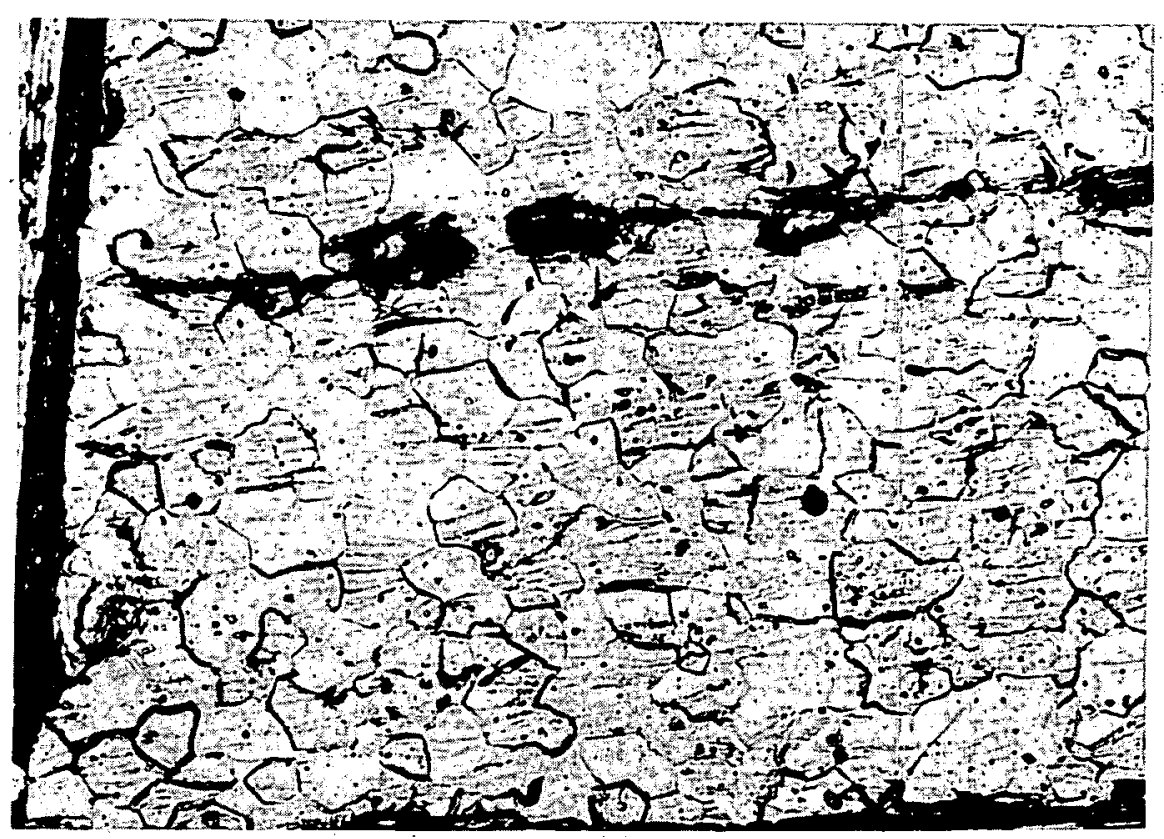

Fig. 13 Same Area as Fig. 12 after 14-Day Corrosion Test. Shows Oxide Surface Corrosion Stringer Forming Directly over the Gas-Void Stringer: Bright Field; $400 \mathrm{x}$

were postulated: (1) A stringer serving as a tunnel through the Zircaloy-2, (2) the joining of one stringer to another through oxidation of the intervening material, (3) continued formation of oxide as a function of time, or (4) the propagation of a crack from the stringer as a result of formation of the oxide within the matrix and the resultant volume increase. Specimens selected from fuel element punchings, corrosion test coupons, and samples representing increasing corrosion test times were examined for evidence of penetration of oxide by means of the postulated mechanisms. On the basis of the work, it was shown that gas-void stringers are discrete and the corrosion product which forms on or in them is restricted to the locale of the stringers; there was no relationship of oxide penetration to time in corrosion test; no oxidized stringers were observed to have propagated a crack. These facts substantiated the conclusion that stringer-type corrosion does not threaten cladding integrity (Ref 19).

In addition to penetration studies, three fuel elements formed from severely stringered material (FZ-614-2) were tested in water for four months at a temperature in excess of $575^{\circ} \mathrm{F}$. Surfaces were in nucleate boiling at $642^{\circ} \mathrm{F}$ (saturation temperature) and operated at a heat flux of approximately $300,000 \mathrm{Btu} / \mathrm{hr}-\mathrm{ft}^{2}$. Post-irradiation examination revealed the surfaces to be covered with the black temper film characteristic of Zircaloy -2 plus some stringer corrosion product. Macroscopic examination revealed no penetration of the cladding. *

Concurrent with the determination of the penetration of stringers, a study of the geometry of an average stringer was made. The dimensions of a typical stringer (Fig. 14) are presented as follows:

\begin{tabular}{lccc} 
& Average (in.) & & Maximum (i \\
\cline { 2 - 2 } Length & 0.0220 & & 0.0700 \\
Width & 0.0007 & & 0.0019 \\
Thickness & 0.0004 & & 0.0006
\end{tabular}

\footnotetext{
* M. D. Novotnak, Bettis Plant, Private Communication
} 


\section{INCHES}

\begin{tabular}{ll}
\hline \multicolumn{1}{c}{ AVE } & \multicolumn{1}{c}{ MAX } \\
0.022 & 0.070 \\
0.0007 & 0.0019 \\
0.0004 & 0.0006 \\
0.0005 & 0.0010
\end{tabular}

A-LENGTH

B-WIDTH

C-THICKNESS

\section{D-PENETRATION FROM ROLLING PLANE EXPOSURE}

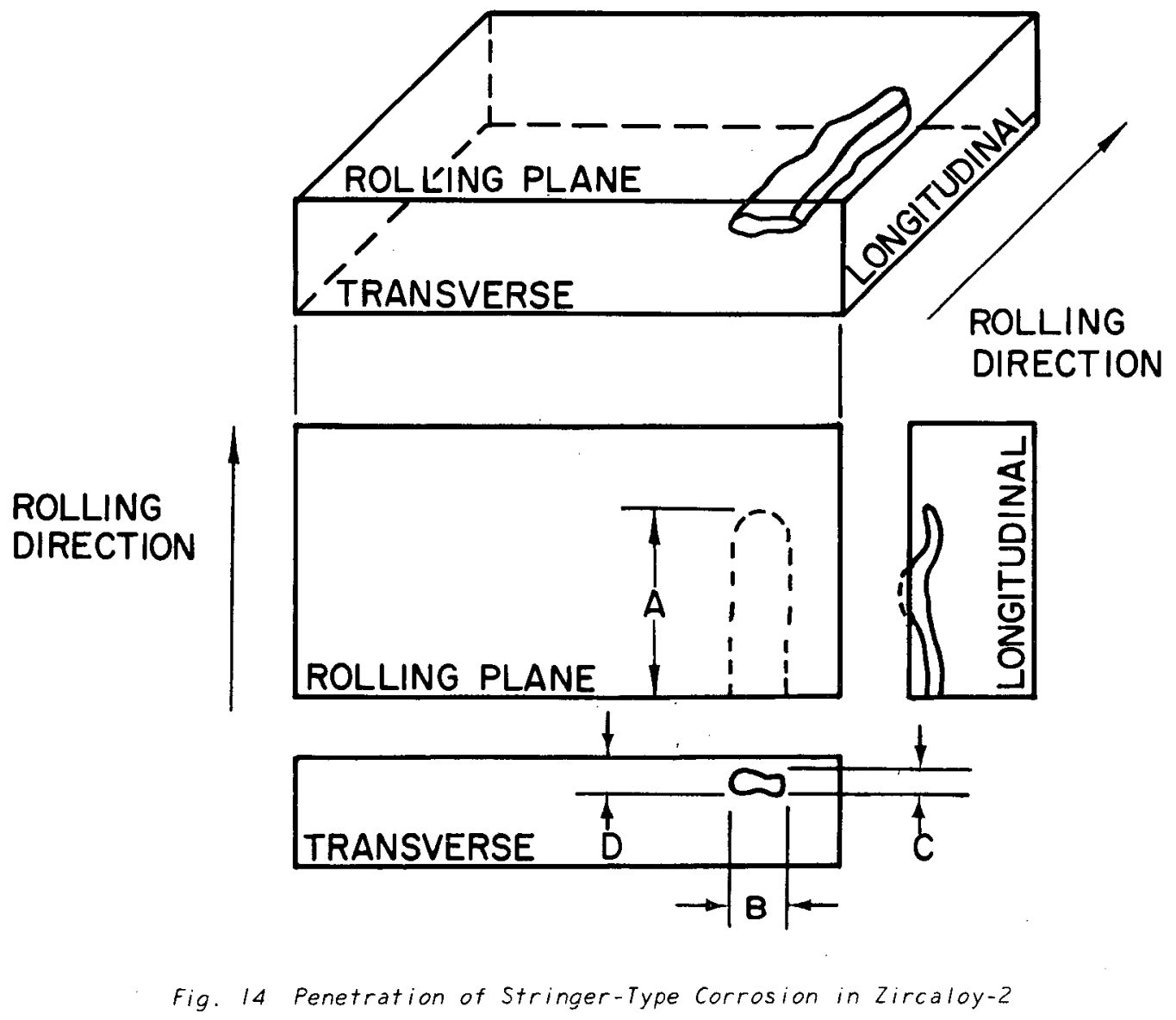

Typical penetrations of stringers from the transverse and longitudinal planes may be seen in Figs. 14 through 17 .

\section{Cooling Rate Studies}

Information on the effects of heat treatment on Zircaloy-3 was utilized to prepare heat treatment programs for Zircaloy-2. Samples of Zircaloy-2 strip known to corrode with stringers were subjected to heat treatments from $1400^{\circ} \mathrm{F}$ to $1900^{\circ} \mathrm{F}$ for times from $1 / 2$ to $8 \mathrm{hr}$. Water quenching, air cooling, and furnace cooling were employed for cooling the samples after heat treatment (Refs 4 and 17). Corrosion testing of these specimens showed that stringer-type corrosion was eliminated by $8-\mathrm{hr}, 1850^{\circ} \mathrm{F}$ (or higher) heat treatments. Shorter times and lower temperatures caused an improvement in the corroded appearance, but the results were not reproducible. The cooling rate was found to have a marked effect on the corrosion weight gain (Refs 13, 17, and 19). Furnace-cooled specimens exhibited weight gains which were two to three times those of duplicate specimens which were 

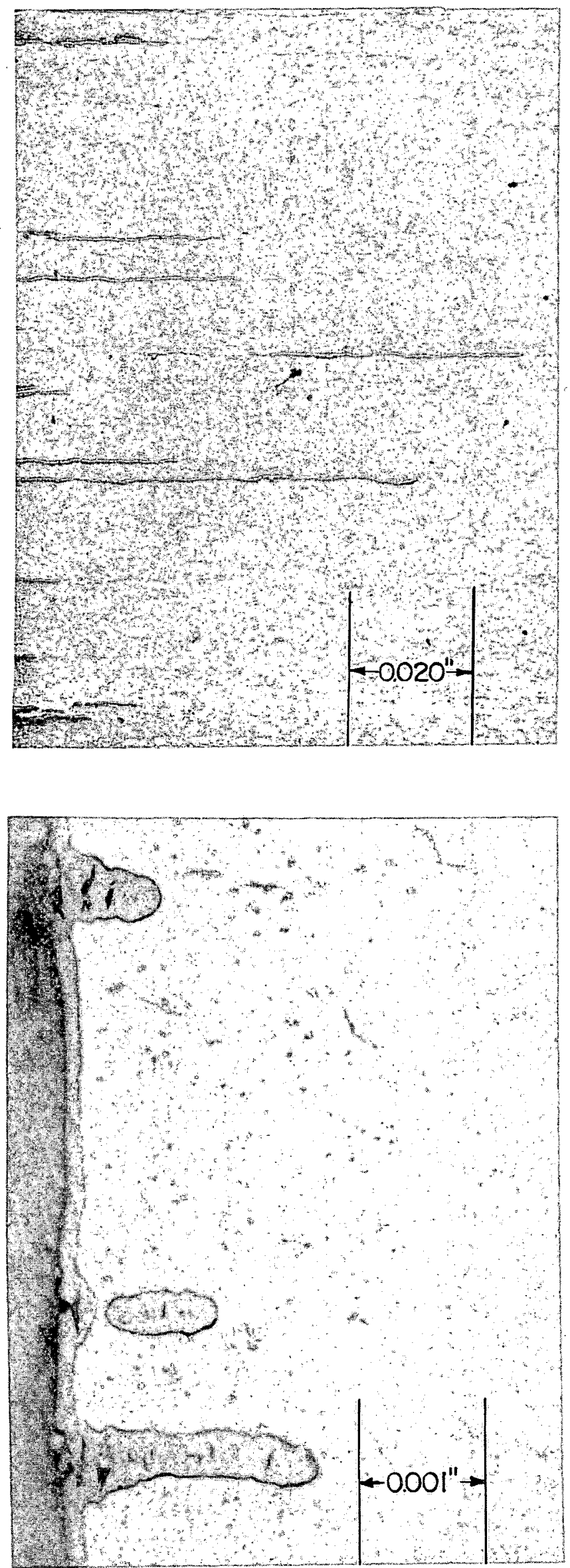

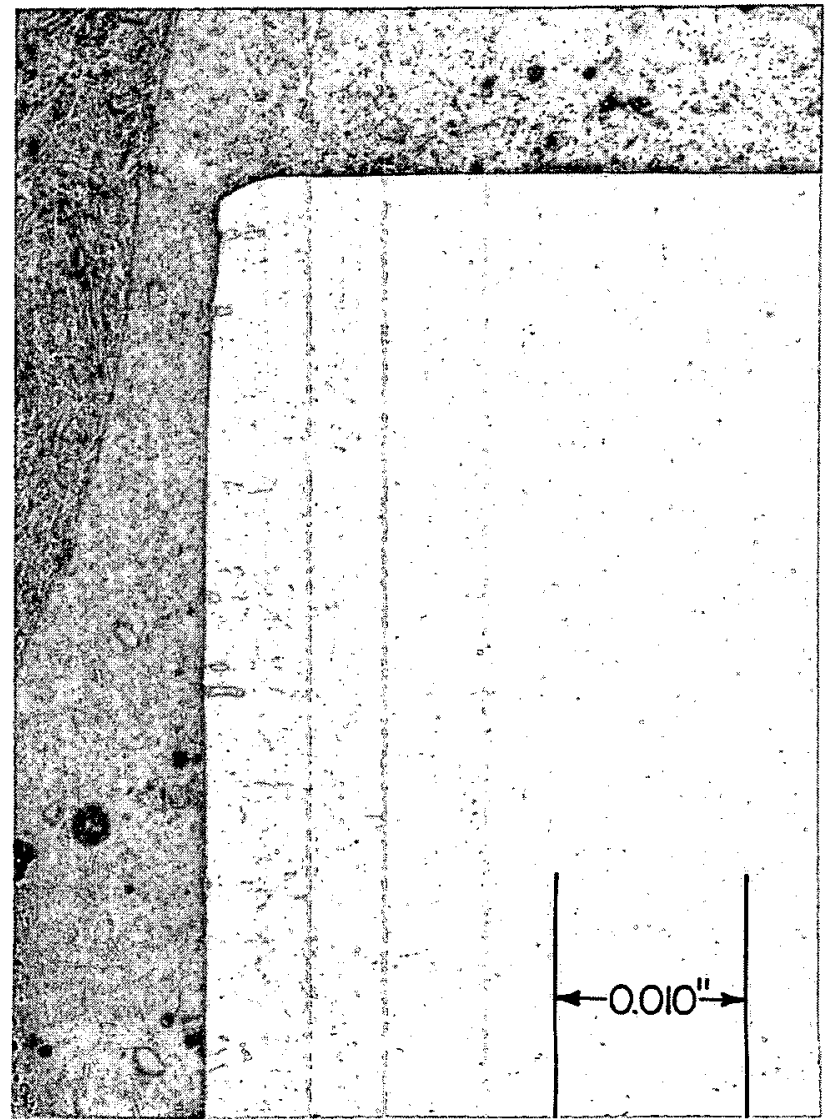

(top left)

Fig. 15 Longitudinal View Showing Penetration of Oxide Caused by Exposing a Stringer to Corrosion on the Transverse Plane; $50 x$

\section{(top right)}

Fig. 16 Transverse View Showing Penetration of Oxide from Stringer Exposed on Longitudinal (Top) Plane. FZ-6/4-2 Corrosion Tested 70 Days in $750^{\circ} \mathrm{F}$ Steam; $75 x$

(left)

Fig. 17 Same View as Fig. 16, Showing Penetration of the Oxide into the Matrix from a Stringer Exposed on the Longitudinal Plane; $750 x$ 
air cooled or water quenched. Metallographic studies were performed to detect differences which could be associated with the corrosion behavior. Longitudinal, transverse, and normal-to-therolling plane views of the specimens were examined. Reasons for reduction or elimination of corrosion-type stringers in these specimens were not evident as the longitudinal views showed microstructural stringers to still exist in the specimens. The normal-to-the-rolling plane view did not show banded precipitate as did the Zircaloy-3. In fact, it was difficult to detect any evidence of stringers when examining this view.

The effect of cooling rate on the microstructure was striking. The air-cooled and water-quenched specimens showed no apparent differences, but they differed from the furnace-cooled ones. The basic differences are listed as follows:

1) Samples heated in the alpha phase region showed no differences, regardless of cooling. The grains were equiaxed and the precipitate was distributed uniformly throughout the matrix and in the grain boundaries.

2) As the heat treatment temperature increased in the alpha plus beta phase region, the rapidlycooled specimens showed increasing amounts of Widmanstatten structure, indicating the existence of prior beta regions. The precipitate, primarily located in the grain boundaries, was present as small discontinuous particles.

The furnace-cooled specimens exhibited grains that were equiaxed or tending to become equiaxed. The grain boundaries were broadened considerably and contained large amounts of precipitate. Above about $1650^{\circ} \mathrm{F}$, the matrix was clear, whereas, below this temperature, the precipitate was dispersed in the matrix. Grain size increased with increasing temperature.

3) Specimens rapidly cooled from the beta phase region showed an all-Widmanstatten structure containing a fine grain boundary precipitate. Those slowly cooled evidenced large equiaxed grains and broad grain boundaries. The grains were clear, but the grain boundaries contained heavy precipitate.

The preliminary studies of the effect of cooling rate on Zircaloy- 2 demonstrated the existence of a cooling rate from the beta phase region above which the corrosion resistance remained satisfactory and below which it decreased. Several statistically designed experiments were performed to determine this critical cooling rate. Strip samples of Zircaloy-2 were heated in Vycor bulbs for $16 \mathrm{hr}$ at $1850^{\circ} \mathrm{F}$, cooled at various rates to $1470^{\circ} \mathrm{F}$, and furnace cooled to room temperature. Statistical interpretation of the weight gain vs cooling rate data after a $14-$ day, $750^{\circ} \mathrm{F}, 1500-\mathrm{psi}$ steam test showed an inflection in the curve at a cooling rate of $90 \mathrm{~F} / \mathrm{min}$. Below this point, the weight gain increased with decreasing cooling rate, and above this point, the cooling rate had no effect on the corrosion weight gain. This behavior is depicted graphically in Fig. 18 . Subsequent work has verified the finding that a cooling rate of $90 \mathrm{~F} / \mathrm{min}$ from $1850^{\circ} \mathrm{F}$ through the alpha plus beta phase region is necessary to ensure the adequate corrosion resistance of Zircaloy-2 (Refs 13 and 21 ).

Because rapidly-cooled Zircaloy-2 had satisfactory corrosion resistance and slowly-cooled Zircaloy -2 had poor corrosion resistance, it was obvious that a cooling rate existed above which corrosion resistance would not be impaired when Zircaloy-2 was cooled from the beta phase. Measurement of the cooling rate for samples encapsulated in Vycor and then air cooled gave a rate of about $600 \mathrm{~F} / \mathrm{min}$ and for furnace cooling about $30 \mathrm{~F} / \mathrm{min}$. Experimental work (Refs 13 and 21 ) sub. stantiated the hypothesis of a critical cooling rate. It was found that the transition for corrosion resistance occurred at approximately $90 \mathrm{~F} / \mathrm{min}$. Figures 18 and 19 depict the effect of cooling rate on the corrosion resistance of Zircaloy -2 .

As mentioned in a previous section, a great deal of the Zircaloy-2 and - 3 work was performed concurrently. When time-temperature studies showed conclusively that the corrosion resistance of 


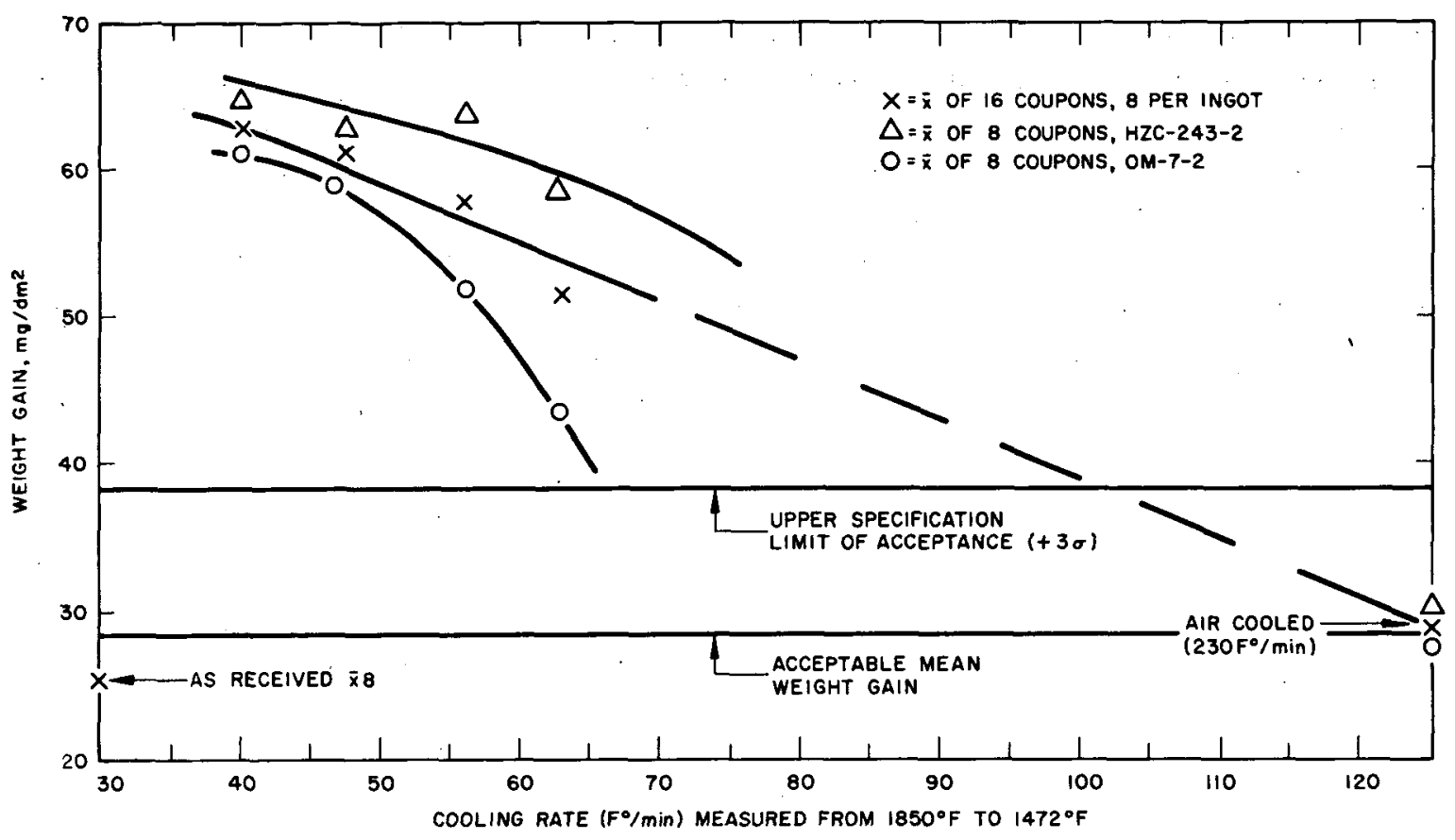

Fig. 18 Critical Cooling Rate.Vacuum-Melted Zircaloy-2; 14 Days, $750^{\circ} \mathrm{F}, 1500$ psi Steam

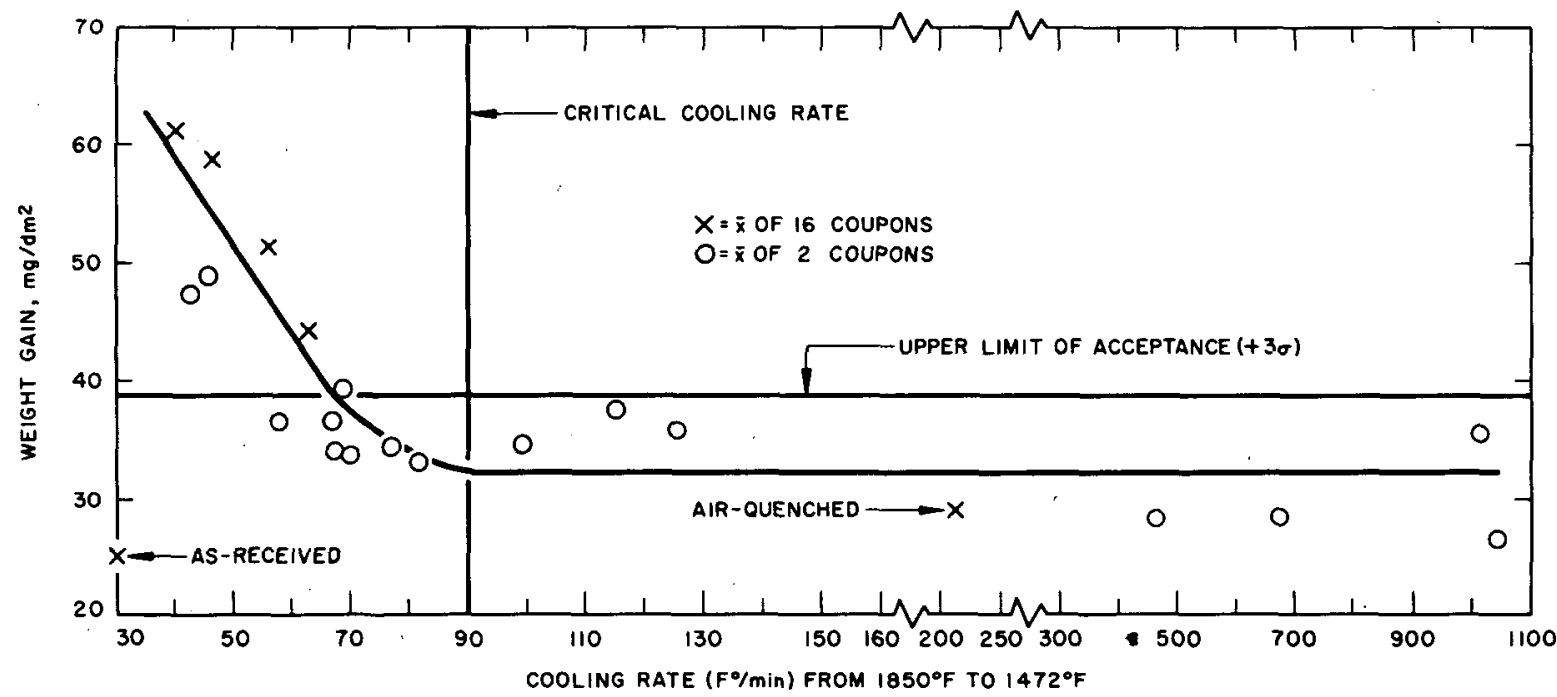

Fig. 19 Critical Cooling Rate vs Height Gain of All Points Heasured; 14-Day, 750 $\mathrm{F}$, 1500 psi Steam Test of Zircaloy-2

Zircaloy -3 which corroded with stringers could be improved with heat treatment and that preliminary information indicated the same to be true for Zircaloy-2, it was decided to homogenize Zircaloy - 2 slabs on a commercial scale in order to eliminate the stringer-type corrosion. It was felt that even if the heat treatment did not improve the corrosion resistance, it would not impair it. Unfortunately, this was not true. The corrosion test results (discussed in the section on Zircaloy-3) showed that the slow cooling of the large mass of metal decreased the corrosion resistance of the Zircaloy- 2 . Cooling rate studies (initiated prior to the commercial homogenization attempts) confirmed, too late, the harmful effects of slow cooling on the corrosion resistance of Zircaloy-2.

It was suspected that subtle changes over the years brought about the reported differences on the effects of heat treatments on corrosion resistance. Prior to the work of Carver and Hayes (Ref 7) 
it had been reported (Ref 12) that the corrosion resistance of Zircaloy-2 was not affected by heat treatment. Yet, reproducible experiments demonstrated that this was incorrect because slow cooling from the beta phase region impaired the corrosion resistance of Zircaloy-2. To determine if the heat treating characteristics of Zircaloy -2 had changed over the years, strip samples from the early Bureau of Mines ingots (dating from 1952) as well as strip samples from ingots melted during the years to 1957 were subjected to beta heat treatments (Ref 4). In all cases, the furnace-cooled specimens showed impaired corrosion resistance, whereas, the air-cooled specimens had weight gains and appearance comparable to those samples with no heat treatment. Apparently, there had been no change in the heat treatment characteristics. Very recent data as yet unpublished, indicate that the corrosion resistance of Zircaloy -2 with a silicon content in the neighborhood of 300 ppm is not as adversely affected by a furnace cool. If the Zircaloy-2 used for the original heat treatment work were high in silicon content (normally less than $100 \mathrm{ppm}$ ), then the reason why no effect of heat treatment was found can be explained.

\section{DISCUSSION}

This discussion is an attempt to tie together the experimental work of the past year and a half and to explain the mechanism of stringer corrosion in Zircaloy-2 and -3 (Refs 10 and 11 ). One thing is evident, two types of microstructural stringers exist in the zirconium alloys under discussion. One type, caused by a gas-void being elongated during fabrication of an ingot, is termed a gas-void stringer. The second type, caused by a continuous grain boundary precipitate, is termed an intermetallic stringer.

An important recent finding shows that corrosion stringers in Zircaloy - 2 are directly related to the microstructural stringers. This is of importance because if the microstructural stringers are eliminated, then the corrosion stringers should be eliminated. Strip from vacuum-melted ingots exhibits far fewer microstructural stringers than does strip from inert atmosphere-melted material (Refs 22 and 23). Sections from vacuum-melted ingots show far less porosity than do sections from atmosphere-melted ingots (Refs 22 and 23). Thus, it is concluded that some of the microstructural stringers are a result of elongation of the gas-voids in the inert atmosphere-melted ingots during fabrication. The microstructural stringers have been shown to contain a precipitate. As yet, the composition of the precipitate has not been determined. However, recent work at Materials Research Corporation * has shown that the precipitate in the stringers is the same precipitate found in the matrix and in the grain boundaries of Zircaloy-2. This work was performed utilizing precipitate chipped out of the matrix and out of the stringers under an inert atmosphere with a Kehl ultrasonic jackhammer. Limited work with an electron probe analyzer at the Naval Research Laboratory indicated that the stringers in Zircaloy-2 contain $8 \%$ to $10 \%$ iron.

Several mechanisms for the formation of precipitate on the wall of the gas-void are possible. The initial precipitation could occur on the wall of the gas-voids during ingot solidification when rejection of the insoluble elements occurs during cooling. The wall of a gas-void in an ingot is a free surface and may be a preferred nucleation site for the precipitate. Heating time for forging and rolling would not be sufficient to permit the precipitate to dissolve. During deformation, the highmelting point, brittle intermetallic compounds would be fractured and probably powdered. In this form, they would prevent the voids from sealing even under the severe bonding pressures of forging and rolling. When examined metallographically, the voids which were originally spherical appear as elongated fissures in the longitudinal view of the strip.

In addition to the possibility that the precipitate powders and does not permit the voids to seal, work by Bostrom (Ref 24) in which argon-atmosphere-melted Zircaloy-2 strip and vacuum-melted Zircaloy-2 were analyzed for gases utilizing a mass spectrometer should be considered. It was

* J. Intrater, Materials Research Corporation, Private Communication 
found that the atmosphere-melted Zircaloy -2 contained more argon than did the vacuum-melted Zircaloy-2. Calculations based on metallographic observations of stringer content and size, and the mass spectrometer information on gas content showed that at room temperature the gas pressure in a void amounts to approximately 0.6 of an atmosphere. At forging and rolling temperatures, this amounts to a pressure in the void of approximately 3 and 2 atmospheres, respectively. Such a pressure is the result of just the rise in temperature. Considering the reduction in volume being forced upon the voids, the gas pressure undoubtedly rises far above this as the result of compression, thus preventing the walls of the void from sealing.

Precipitate could form on the walls of the void upon cooling. One of the most interesting observations of metallographic structures is that the gas-void stringers are surrounded by alpha grains which are the last to transform to beta upon heating through the alpha plus beta region to the beta phase (Ref 25). This can be explained by postulating that the areas adjacent to the stringers have been depleted of iron, nickel, and chromium. Since these elements lower the transformation temperature, the depleted areas would have a higher transformation temperature than the surrounding material and would be the last to become beta during heating. Another possibility is that these areas are enriched in tin, nitrogen, or oxygen which raise the transformation temperature.

Depleted areas are more likely to be present than enriched areas. Two facts were used to deduce this. First, the electron probe analyzer showed $8 \%$ to $10 \%$ iron in the gas-void stringer. Second, the existence of the theta phase was found from a study of the zirconium, tin, iron diagram (Ref 26 ). This phase has a solubility for iron of up to $7.5 \mathrm{w} / \mathrm{o}$ (Ref 27 ).

These two isolated findings can be pieced together. Assuming one of the precipitates in the gasvoid is theta, this area would be enriched in tin and would have about $7.5 \mathrm{w} / 0$ iron in solution with it. Since chromium and nickel are similar in behavior to iron, it could be assumed that they will also be soluble to some extent in the theta phase. The evidence that iron is present in amounts close to the solubility limit of iron in the theta phase may indicate that the major precipitate in the gas-void is theta. Since there is no obvious reason for nitrogen or oxygen to locate in and around gas-voids, it is likely that the areas around the stringers remain alpha because they are depleted in iron, chromium, and nickel. The corrosion stringers are probably caused by the corrosion of the theta in the stringer and/or corrosion of areas of low iron, chromium, and nickel surrounding the stringers.

The suspicion that the depleted area corrodes rather than the precipitate is based on the fact that pure zirconium, when it corrodes, corrodes white. In addition, the alpha areas would tend to be higher in nitrogen than normal because of the higher solubility for nitrogen in the alpha phase rather than in the beta phase. Nitrogen is known to accelerate the corrosion of Zircaloy. By heating material in the beta phase $\left(1850^{\circ} \mathrm{F}\right)$ and holding it at this temperature for $8 \mathrm{hr}$, the concentration gradients are evened out by diffusion. Quenching causes the elements to be retained uniformly throughout the structure and gives good corrosion resistance. However, slow cooling through the alpha plus beta region allows partitioning of the elements. Thus, the last areas to transform to alpha would be highly enriched in the alloying elements iron, chromium, and nickel and the first to transform would be highly enriched in tin, oxygen, and nitrogen. At the lower alpha temperatures, these elements would not be able to diffuse to eliminate concentration gradients. The iron, chromium, and nickel would precipitate heavily into grain boundary regions and would cause corrosion either in the grain boundaries, high in alloying elements, or in the grains which are depleted of iron, chromium, and nickel and enriched in tin, oxygen, and nitrogen, or both. The hypothesis presented above is supported by the poor corrosion resistance of material slow cooled to room temperature from the beta.

The possibility that the elimination of stringer-type corrosion by heat treatment was just a surface effect was shown to be incorrect (Ref 11). Specimens which had not been subjected to 
homogenization were also step machined. Both groups of specimens were corrosion tested for 14 days in $750^{\circ} \mathrm{F}$ steam. The specimens without heat treatment exhibited stringer-type corrosion on all surfaces, whereas, the heat-treated ones showed no stringer-type corrosion. It has been shown earlier in the report why Zircaloy-2 corrodes with stringers and yet has few gas-void stringers. Zircaloy - 3 corrodes by a different mechanism than does Zircaloy-2. The stringers in Zircaloy-3 were caused by segregated grain boundary precipitate, whereas, the stringers in Zircaloy-2 that corroded were caused by gas-voids. The question as to whether the stringers will harm Zircaloy in service has been answered by sectioning Zircaloy-2 strip which was heavily stringered and by examining the surfaces to determine the depth of the stringers. Data were collected and statistically analyzed; it was shown that the stringers did not in any case exceed $10 \mathrm{mils}$ in depth of penetration (in general, cladding for fuel elements is about $30 \mathrm{mils}$ ).

The theory of corrosion stringers in atmosphere-melted Zircaloy-2 may be summarized $/$ as follows: (1) Gas-voids formed during inert-atmosphere melting become stringers during fabrication, (2) the walls of the gas-voids are covered with a precipitate which was formed during the solidification of the ingot or during fabrication of the ingot, (3) this precipitate is possibly theta with $7.5 \mathrm{w} / \mathrm{o}$ iron and probably some nickel and chromium dissolved in it, (4) the voids do not seal during fabrication because of the pressure built up by the entrapped inert gas, and (5) when Zircaloy-2 strip is machined the stringers are opened up, and when exposed to water during the corrosion test, the precipitate, or an area adjacent to the stringer which has been depleted of iron, chromium, and nickel corrodes faster than the matrix. Because these areas of precipitate or depletion are discrete, the white corrosion does not progress with longer exposures.

\section{ACKNOWLEDGMENTS}

The authors take this opportunity to thank Messrs. E. L. Richards, F. R. Lorenz, and Dr. D. E. Thomas, WAPD, Dr. M. L. Picklesimer, ORNL, Dr. D. W. Levinson, ARF, Dr. R. B. Gordon, AI, Drs. S. Weinig and J. Intrater, MRC, as well as other persons too numerous to mention, for their assistance, guidance, and cooperation during the course of this work.

\section{REFERENCES}

1. R. B. Gordon, "Stringer-Type Corrosion of Zircaloy-2," Bettis Atomic Power Division Report WAPD-NCE-3975 (July 10, 1957).

2. J. G. Goodwin and E. L. Richards, "Progress in the Resolution of Anomalous Zirconium Alloy Corrosion Problems," Bettis Technical Review, WAPD-BT-2 (July 1957) pp 59-70.

3. J. G. Goodwin, "Second Interim Report on the Zirconium Alloy Corrosion Problem," Bettis Atomic Power Division Report WAPD-NCE-4512 (June 24, 1957).

4. J. G. Goodwin, "Third Interim Report on the Zirconium Alloy Corrosion Problem," Bettis Atomic Power Division Report WAPD-NCE-5777 (August 22, 1957).

5. S. Kass, "The Effect of Removal of Surface Metal," Zirconium Highlights, WAPD-ZH 1 (November 1957), pp 22-23.

6. S. Kass, D. J. Fontanese, A. E. Oaks, and D. B. Scott, "Pickling of Zircaloy Prior to Corrosion Exposure," Bettis Atomic Power Division Report WAPD-TM-141 (September 1958).

7. M. D. Carver and E. T. Hayes, "The Effect of Microstructure on the Corrosion Rate of Alloys of Zirconium," USBM-U-123 (June 1, 1956).

8. M. L. Picklesimer, "The Microstructural Appearance of Stringers in Zircaloy-2," Zirconium Highlights, WAPD-ZH-2 (December 1957), pp 23-33.

9. M. L. Picklesimer and G. M. Adamson, "Development of a Fabrication Procedure for Zircaloy-2," ORNL-56-11-115 (November 21, 1956). 
10. J. G. Goodwin, "A Postulation on the Source of Stringer Corrosion in Zircaloy-2," Zirconium Highlights, WAPD-ZH-3 (January 1958), pp 5-9.

11. J. G. Goodwin, J. G. Grozier, L. S. Rubenstein, and F. L. Shubert, "Technology Section Quarterly Progress Report on Metallurgical Studies of Zirconium Alloys, "Bettis Atomic Power Division Report WAPD-NCE-7002 (November 19, 1957).

12. B. Lustman and F. Kerze, Jr. (eds.), The Metallurgy of Zirconium (New York: McGraw-Hill Book Co., Inc. , 1955).

13. J. G. Goodwin, J. D. Grozier, L. S. Rubenstein, and F. L. Shubert, "Quarterly Progress Report," Bettis Atomic Power Division Report WAPD-NCE-9040 (July 15, 1958).

14. J. G. Goodwin, "The Effect of Heat Treatment on the Tensile and Corrosion Properties of Zircaloy-2, "Zirconium Highlights, WAPD-ZH-5 (March 1958), pp 10-13.

15. J. G. Goodwin, "Further Studies on the Effect of Heat Treatment on the Tensile and Corrosion Properties of Zircaloy-2," Zirconium Highlights, WAPD-ZH-8 (June 1958), pp 3-4.

16. J. Chirigos and K. M. Goldman, "Summary of Calculations on the Diffusion of Gaseous Contaminants in Zircaloy, "Zirconium Highlights, WAPD-ZH-1 (November 1957), pp 11-13.

17. J. G. Goodwin, "The Effect of Heat Treatment on the Corrosion Resistance of Zircaloy-2 and Zircaloy-3," Bettis Technical Review, WAPD-BT-6 (January 1958), pp 39-47.

18. J. Intrater, "Dilatometric Investigation of Vacuum-Melted Zircaloy-2, " Zirconium Highlights, WAPD-ZH-7 (May 1958), pp 1-13.

19. J. G. Goodwin, J. D. Grozier, L. S. Rubenstein, and F. L. Shubert, "Progress Report on Metallurgical Studies of Zirconium Alloys," Bettis Atomic Power Division Report WAPD-NCE7532 (February 15, 1958).

20. J. D. Grozier, "Evolution of Stringers in Zircaloy -2," Zirconium Highlights, WAPD-ZH-4 (February 1958), pp 18-23.

21. L. S. Rubenstein, "Relationship of Cooling Rate to the Corrosion Resistance of Zircaloy-2," Zirconium Highlights, WAPD-ZH-8 (June 1958), pp 1-3.

22. J. H. Hart, "Vacuum- vs Atmosphere-Melting of Zirconium Alloys, "Zirconium Highlights, WAPD-ZH-2 (December 1957), pp $15-22$.

23. L. F. Cochrun and E. L. Richards, "Vacuum-vs Atmosphere-Melted Zircaloy," Zirconium Highlights, WAPD-ZH-1 (November 1957), pp 15-20.

24. W. A. Bostrom, "Characteristics of Stringers in Zircaloy-2," Zirconium Highlights, WAPDZH-12 (November 1958), pp $1-9$.

25. J. G. Goodwin, "Preliminary Study of the Alpha to Alpha-Plus-Beta Transformation Temperature for Zircaloy-2," Zirconium Highlights, WAPD-ZH-2 (December 1957), pp 34-41.

26. L. E. Tanner and D. W. Levinson, "The System Zirconium-Iron-Tin," ARF-2068-4 (August 12, 1957).

27. L. E. Tanner and D. W. Levinson, "The System Zirconium-Iron-Tin," ARF-2068-5 (July 29, $1958)$. 